Bundesgesundheitsbl 2013 -56:957-984

DOI 10.1007/s00103-013-1777-3

(c) Springer-Verlag Berlin Heidelberg 2013

J. Koch ${ }^{1} \cdot$ M. Wiese-Posselt ${ }^{1} \cdot$ C. Remschmidt ${ }^{1}$ O. Wichmann ${ }^{1} \cdot$ H. Bertelsmann ${ }^{2} \cdot$ E. Garbe ${ }^{3} \cdot$ H. Hengel ${ }^{4} \cdot$ J.J. Meerpohl ${ }^{5} \cdot$ A.Mas Marques $^{6} \cdot$ H. Oppermann ${ }^{7}$. E. Hummers-Pradier ${ }^{8} \cdot \mathrm{R}$. von $\mathrm{Kries}^{9} \cdot \mathrm{T}_{\text {. Mertens }}{ }^{10}$

${ }^{1}$ Immunization Unit, Robert Koch Institute, Berlin

${ }^{2}$ Fachhochschule der Diakonie, University of Applied Sciences, Bielefeld

${ }^{3}$ Bremen Institute for Prevention Research and Social Medicine, University of Bremen

${ }^{4}$ Institute for Medical Microbiology and Hygiene, Department of Virology, University Medical Center Freiburg

${ }^{5}$ German Cochrane Centre, Institute of Medical Biometry and Medical Informatics, University Medical Center Freiburg

${ }^{6}$ Division 15: Viral Gastroenteritis and Hepatitis Pathogens and Enteroviruses, Robert Koch Institute, Berlin

${ }^{7}$ State Office for Consumer Protection, Saxony-Anhalt, Magdeburg

${ }^{8}$ Department of General Practice/Family Medicine, University Medical Centre Goettingen, Georg-August-University, Goettingen

${ }^{9}$ Institute of Social Paediatrics and Adolescent Medicine, Ludwig-Maximilians University of Munich

${ }^{10}$ Institute of Virology, Ulm University Medical Center, UIm

\title{
Background paper to the recommendation for routine rotavirus vaccination of infants in Germany
}

the World Health Organization's Strategic Advisory Group of Experts on immunization (SAGE) recommended the introduction of RV vaccines in all national immunization programs [6]. This paper presents the scientific background, which supported the decision-making process of the German Standing Committee on Vaccination (STIKO) related to a recommendation on routine $\mathrm{RV}$ vaccination in Germany. In alignment with the STIKO set of key questions and the STIKO Standard Operating Procedures [91], this background paper summarizes results of systematic reviews of the literature focusing on efficacy, effectiveness, impact and safety of RV vaccines, as well as on the local epidemiology of RV infections in Germany. In the accompanying appendices additional information regarding the conducted systematic reviews is presented. The appendices are available online and can be downloaded from the RKI website (http://www:stiko.de/en).

\section{Rotavirus disease and epidemiology}

\subsection{Virology, morphology and laboratory diagnosis}

RVs are non-enveloped, double-stranded segmented RNA viruses which are members of the family Reoviridae, consisting of three concentric capsid layers that enclose the genomic RNA [7]. RVs are classified into seven serogroups (A-G), but only three groups $(\mathrm{A}-\mathrm{C})$ affect humans $[8,9]$. Serogroup A is clinically the most important serogroup and responsible for diarrhoeal disease worldwide. Within

Judith Koch, Miriam Wiese-Posselt, Cornelius Remschmidt, Ole Wichmann: Executive Secretariat of the German Standing Committee on Vaccination (STIKO). Hilke Bertelsmann, Edeltraut Garbe, Hartmut Hengel, Hanna Oppermann, Eva Hummers-Pradier, Rüdiger von Kries, Thomas Mertens: Members of STIKO. 


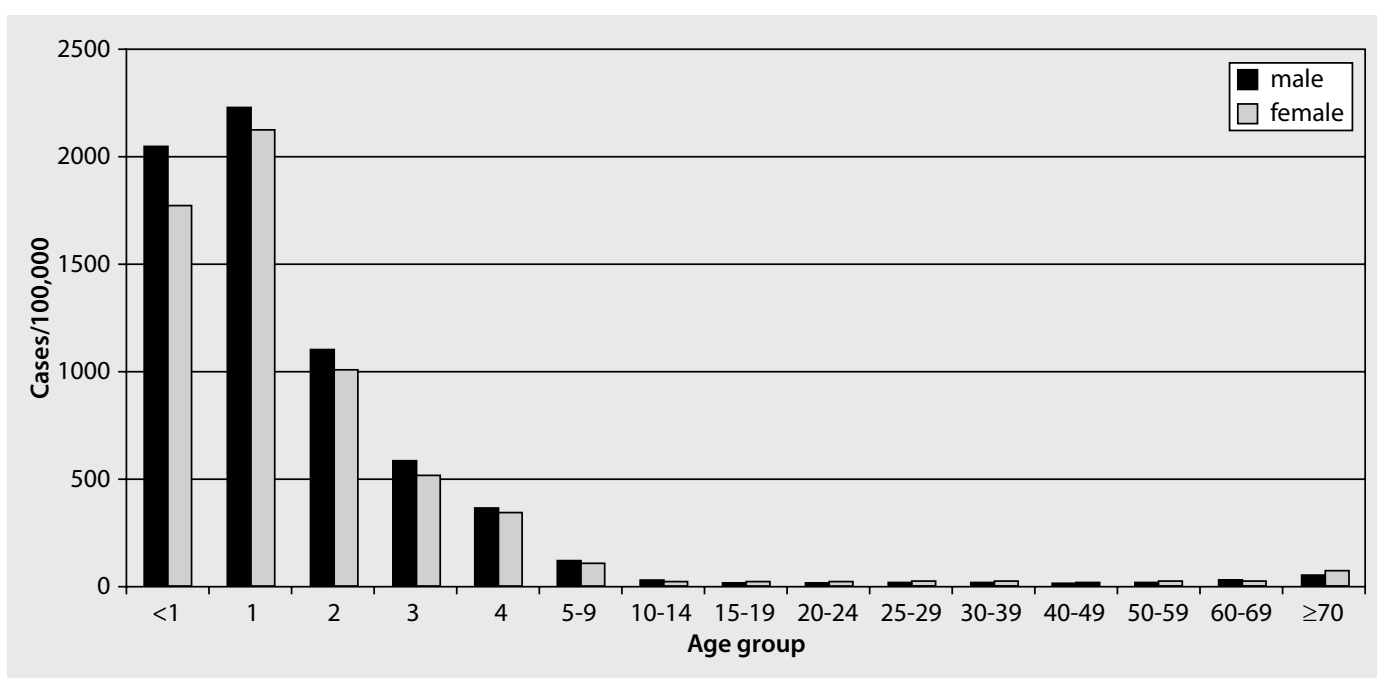

Fig. $1<$ Mean annual incidence of reported rotavirus infections by age group, Germany, 2006-2010 group A, RV serotypes are further classified into G- (glycoprotein antigen) and P-types (protease-sensitive antigen) on the basis of their surface proteins VP7 and VP4, respectively. Both antigens are thought to be important for protection and critical for vaccine development [7]. To date, 24 different $\mathrm{G}$ - and 33 different $\mathrm{P}$ types have been detected $[10,11]$.

EuroRotaNet, a European laboratory network with 16 participating countries, found that G1P [8], G2P [4], G3P [8], G4P [8], G9P [8] were the most prevalent human RV genotypes across Europe [12]. However, there was a huge diversity of cocirculating strains, and the prevalence of the different RV types varied geographically and from year to year. In temperate regions, a clear seasonal trend of RV infections can usually be observed in the majority of countries with peak virus circulation in late winter and early spring $[5,13]$.

Laboratory confirmation of RV infection can be obtained by detection of the virus, viral antigen or viral RNA in stool samples. The most commonly used method is antigen detection by one of several commercially available enzyme immunoassays (EIA), which are easy to perform and provide a low detection limit $[14,15]$. Other techniques include realtime PCR and electron microscopy.

\subsection{Transmission}

$\mathrm{RV}$ is transmitted by the faecal-oral route. It is a highly contagious pathogen that remains infectious on hands for sev- eral hours and on environmental surfaces for a prolonged time (days to weeks) $[16,17]$. Because of its considerable resistance to disinfectants and hand-washing agents [18], a small minimum infectious dose [19], and a high virus concentration in stool (up to $10^{12}$ virus particle/g stool during acute illness) [20], there is only a weak association between RV incidence and the level of economic development or hygiene measures [21]. Furthermore, due to these characteristics, virus spread within families is common and hospital-acquired outbreaks occur and are difficult to control making RV also an important cause of nosocomial infections [22, 23, 24].

\subsection{Pathogenesis and clinical features of RV disease}

$\mathrm{RV}$ infects cells of the small intestine and produces a number of non-structural (NS) proteins enhancing viral replication, disarming the natural immune response, and manipulating cellular signalling pathways [25]. Among the NS proteins an enterotoxin, NSP4, destroys intestinal mucosa cells $[26,27]$ resulting in severe watery diarrhoea. After an incubation period of usually $<48 \mathrm{~h}$, clinical symptoms include acute onset of vomiting and fever followed by watery diarrhoea $[28,29]$. The disease spectrum ranges from a mild, short-lasting course to severe and dehydrating diarrhoea that may lead in rare circumstances to complications such as seizures, CNS involvement, or even death $[30,31,32]$. In RV- infected patients, diarrhoea and vomiting is more common and prolonged than in paediatric gastroenteritis caused by other pathogens, and fever is reported in 30$70 \%$ of children $[33,34,35,36,37,38]$. Gastrointestinal symptoms resolve usually in $<7$ days, and at 1-month followup $88 \%$ of children have returned to their usual health status [39]. Treatment of RV disease consists mainly of oral or intravenous rehydration [40]. However, chronic diarrhoea and extraintestinal manifestations have been observed, particularly in immunocompromised individuals with conditions such as severe combined immunodeficiency (SCID), acquired immunodeficiency syndrome (AIDS), and DiGeorge syndrome [41, 42]. In addition, patients suffering from congenital immunodeficiency or immunosuppression due to bone marrow or solid organ transplantation are at risk for more severe or prolonged RV disease [43, 44]. In contrast, several studies have shown that breast feeding can protect against symptomatic RV infection [45, 46, 47, 48]. One study has shown that the risk of hospitalization due to RV gastroenteritis (RVGE) was associated with lack of breast feeding, low birth weight, attending child care, and presence of another child $<24$ months of age in the same household [49].

\subsection{Epidemiology of RV disease}

$\mathrm{RV}$ is the most common cause of severe dehydrating diarrhoea worldwide, resulting in more than 2 million hospitalizations and 453,000 deaths (95\% CI 
Bundesgesundheitsbl 2013 · 56:957-984 DOI 10.1007/s00103-013-1777-3

(c) Springer-Verlag Berlin Heidelberg 2013

J. Koch · M. Wiese-Posselt · C. Remschmidt · O. Wichmann · H. Bertelsmann · E. Garbe · H. Hengel · J.J. Meerpohl • A.M. Marques · H. Oppermann · E. Hummers-Pradier · R. von Kries · T. Mertens Background paper to the recommendation for routine rotavirus vaccination of infants in Germany

\section{Abstract}

Two rotavirus (RV) vaccines were introduced to the European market in 2006. To support the decision-making process of the German Standing Committee on Vaccination ("Ständige Impfkommission", STIKO) regarding adoption of routine $\mathrm{RV}$ vaccination into the national vaccination schedule in Germany relevant scientific background was reviewed. According to STIKO's Standard Operating Procedures for the development of evidencebased vaccination recommendations, a set of key questions was addressed and systematic reviews were performed with a focus on the efficacy, effectiveness, impact and safety of RV vaccines. The Grading of Recommendations Assessment, Development and Evaluation (GRADE) methodology was applied to assess the quality of available evidence. Da- ta from 5 randomized controlled trials demonstrated a high efficacy of RV vaccines in preventing severe RV-associated gastroenteritis (91\%) and hospitalization (92\%) in settings comparable to Germany. Post-marketing observational studies confirmed these findings. In several countries, impact studies suggest that age groups not eligible for vaccination might also benefit from herd effects and demonstrated a decrease in the number of nosocomial RV infections after RV vaccine introduction. The vaccines were considered safe, except for a slightly increased risk of intussusception shortly after the first dose, corresponding to 1-2 additional cases per 100,000 infants vaccinated (relative risk $=1.21$, 95\% confidence interval [Cl] 0.68-2.14). RV case-fatality is extremely low in Germa- ny. However, RV incidence among children aged $<5$ years is high (reported $8-14$ cases per 1000 children annually), and of these almost half require hositalization. In view of the available evidence and expected benefits, STIKO recommends routine rotavirus vaccination of children under the age of 6 months with the main goal of preventing RV-associated hospitalizations in Germany, especially among infants and young children.

Keywords

Rotavirus vaccination · Rotavirus

gastroenteritis · Vaccination recommendation $\cdot$ Standing committee on vaccination (STIKO) · Germany

\section{Hintergrundpapier zur Empfehlung für die Rotavirus-Standardimpfung von Säuglingen in Deutschland}

\section{Zusammenfassung}

Zwei Rotavirus (RV)-Impfstoffe sind seit 2006 auf dem europäischen Markt verfügbar. Um die Ständige Impfkommission (STIKO) bei ihrer Entscheidungsfindung zu unterstützen, ob sie die RV-Impfung als Standardimpfung in den Impfkalender aufnehmen soll, wurde der diesbezügliche wissenschaftliche Hintergrund aufgearbeitet. Nach der STIKO-Standardvorgehensweise für die systematische Entwicklung von evidenzbasierten Impfempfehlungen wurden dazu Aspekte des STIKO-Fragenkatalogs bearbeitet sowie systematische Reviews zu Wirksamkeit, Effektivität, Impact und Sicherheit der RV-Impfstoffe durchgeführt. Dem Ansatz der "Grading of Recommendations Assessment, Development and Evaluation" (GRADE)-Methodik folgend, wurde die Qualität der verfügbaren Evidenz bewer- tet. Daten von 5 randomisierten klinischen Studien zeigten, dass in Ländern, die mit Deutschland vergleichbar sind, durch die RV-Impfung schwere RV-Gastroenteritiden (Wirksamkeit $=91 \%)$ und Hospitalisationen (92\%) verhindert werden können. Daten aus Postmarketingstudien bestätigten diese Ergebnisse. Impact-Studien verschiedener Ländern zeigen zusätzlich, dass die Zahl der nosokomialen RV-Infektionen nach Einführung der RV-Impfung zurückgegangen ist und dass möglicherweise auch Altersgruppen, die nicht geimpft werden, durch Herdeneffekte von der Impfung profitieren. Die Impfstoffe werden generell als sicher bewertet. Es besteht jedoch ein gering erhöhtes Invaginationsrisiko von 1 bis 2 zusätzlichen Fällen pro 100.000 geimpfte Kinder kurz nach der ersten RV-Impfdosis (relatives Risiko

\begin{abstract}
$=1,21 ; 95 \%-K I 0,68-2,14)$. Todesfälle infolge von RV-Infektionen sind in Deutschland äußerst selten. Die RV-Inzidenz bei Kindern im Alter unter 5 Jahren ist jedoch hoch ( 8 bis 14 berichtete Fälle pro 1000 Kinder jährlich), von diesen wird fast die Hälfte stationär behandelt. Angesichts der guten verfügbaren Evidenz und des zu erwartenden Nutzens empfiehlt die STIKO die routinemäßige RVImpfung von Kindern im Alter unter 6 Monaten mit dem primären Ziel, RV-assoziierte Hospitalisationen insbesondere bei Säuglingen und Kleinkindern zu verhindern.
\end{abstract}

Schlüsselwörter

Rotavirus-Impfung ·

Rotavirus-Gastroenteritis · Ständige

Impfkommission (STIKO) · Impfempfehlung • Deutschland
$420,000-494,000)$ in children $<5$ years $[1$, $2,50]$. The virus affects almost all children within the first 5 years of life [51,52], with a peak incidence in children younger than 2 years of age $[5,53,54]$. Young infants are believed to be partly protected by maternal antibodies acquired transplacentally or via breast feeding $[55,56]$. However, individuals can be infected with RV repeatedly during their life, with reduced severity in subsequent infections [57]. In Germany, laboratory-confirmed $\mathrm{RV}$ infection in individuals presenting with diarrhoea and/or vomiting is notifiable according to the German Protection against Infection Act since 2001 [58]. The age distribution of patients reported with laboratory RV infections per 100,000 population is shown in $\bullet$ Fig. 1. Between 2001 and 2008, RV infection was the most frequently reported infectious disease in children aged $<5$ years [5]. The annually reported number of cases in this age group ranged from 28,100 to 47,600 corresponding to an incidence of $820-1,380$ per 100,000 children. However, these numbers are likely to underestimate the true disease burden, because (1) mild or moderate RV infections are often managed at home without healthcare consul- 




Fig. $2<$ Numbers of children aged $<5$ years treated for rotavirus gastroenteritis in hospital or as outpatients by month, Germany, 2001-2010 tation, and (2) result from laboratory testing of stool specimen does not influence treatment decisions, thus testing is usually not performed by physicians [59].

According to national notification data, $45 \%$ of reported cases $<5$ years of age were hospitalized or acquired nosocomial infection, leading to an average of 17,600 hospitalisations each year (incidence 510/100,000). In this age group, RV was responsible for $70 \%$ of all hospitalizations reported to be associated with one of the notifiable infectious agents causing acute gastroenteritis (AGE) in Germany (i.e RV, Shigella spp, Salmonella spp, Yersinia spp, Giardia lamblia, norovirus, Campylobacter spp, E. coli, and enterohemorrhagic E. coli) [5].

RV infection leading to hospitalization is reported over the entire year with a clear seasonal trend and a dominant late winter and spring peak from January to May (- Fig. 2). Approximately $75 \%$ of hospitalized cases were $\leq 2$ years of age and the proportion of nosocomial infections ranged from 8.6 to $13.3 \%$ in children $<2$ years of age.

Fatal RV-cases are very rare in Germany. Between 2004 and 2008, only 8 deaths were attributable to RV infection in children $<5$ years of age [5]. An active surveillance study was performed within the ESPED infrastructure (a hospital network in Germany) between April 2009 and March 2011 to identify severe courses of RV diseases in hospitalized children [60]. A severe course of RV disease was defined by either intensive care treatment, hyper- or hyponatremia ( $>155 \mathrm{mmol} / \mathrm{l}$ or $<125 \mathrm{mmol} / \mathrm{l}$ ), clinical signs of encephalopathy (somnolence, seizures, apnoea) or death due to RV disease. The annual incidence of community-acquired severe $\mathrm{RV}$ infections in children aged $<5$ years was estimated at 1.2/100,000. This figure presents a minimum level estimate because no adjustment for underreporting was possible.

\subsection{Reassortment of RV strains}

Co-infections with more than one strain are possible and can lead to the emergence of reassortant RV variants [61, 62, 63]. Although animal species (e.g. calves and pigs) are susceptible to RV infections $[64,65]$, animal-to-human transmission appears to be uncommon $[9,12]$. However, both natural reassortant animal-human strains and direct zoonotic transmission have been observed $[12,63,66]$. Reassortment can occur when different RVA strains replicate in a cell, and a mix of their genome segments is packaged into new virus particles. As a result, the hybrid RV-A virions exhibit characteristics of their parental strains. In some cases, especially if the hybrid strain gains heterologous VP4 or VP7 encoding genes from a zoonotic strain, this hybrid strain may evade type-specific human immune response [65, 66]. The RV-A proteins are coded by 11 separate genome segments. Leading to reassortment of gene segments, the segmentation of RV-A genome significantly contributes to anti- genic shift. Human G9 strains and recently emerging G12 strains are examples for hybrid RV-A strains that have acquired antigens from animal RV and spread worldwide within a few years [67]. The proportion of hybrid strains (including G12) in Europe was approximately 1-2\% in 2006-2009 [12].

Emergence of new RV-A strains, and regionally and seasonally changing frequencies of RV-A types are a natural phenomenon that occurs independently of vaccination $[68,69]$. Common trends are observed in samples from different regions, as data from EuroRotaNet show [12]. In the season 2007/08, an increase of G1P[8] was found in samples from different European countries. While G1P [8] decreased in the subsequent season 2008/9 in most countries, more infections with G4P[8] were observed. In 2005/6, before the introduction of $\mathrm{RV}$ vaccination, G9P [8] was identified as one of the most frequent genotype combinations in Germany and other countries for the first time [70, 71]. Phylogenetic analyses indicate that G9 strains have emerged from a common origin approximately 20 years ago and then spread worldwide within only a few years [67]. A similar emergence is currently being observed for G12 strains [67].

As of today, it is not clear how effective currently available $\mathrm{RV}$ vaccines that are designed to protect against group A RV strains will prevent illness from newly emerging RV-A strains. The influence of other RV-A antigens on immunity re- 
mains unclear $[68,72]$. Antibodies targeting VP6 and other RV-A antigens possibly contribute to immunity and reduce the relevance of heterologous VP4 and VP7 (heterotypic immunity).

Natural fluctuation of RV-A genotypes complicates the identification of changed frequencies of strain occurrence potentially induced by vaccination (replacement). Genetic drift could disguise replacement, possibly undetectable by $\mathrm{G}$ and $P$ typing [73]. Studies from Belgium, Brazil, Australia and the USA have reported increased frequencies of G2 and G3 strains after introduction of routine RV vaccination [74, 75, 76, 77, 78]. However, the authors discussed their findings cautiously because the time interval since introduction of RV vaccination was too short to clearly differentiate between natural fluctuations and replacement due to vaccination. This differentiation requires long-term surveillance of circulating RV-A strains and additional sequencing of defined genome segments $[68,69]$.

\section{Rotavirus vaccines}

In 1998, the first RV vaccine (Rotashield ${ }^{\circledR}$ ) was licensed and available only on the US market [79]. It was withdrawn from the market within 1 year after its introduction as an association with intussusception had been observed [80]. Study data demonstrated that the risk of intussusception increased with age at the 1st dose [81]. Seven years after the withdrawal of the first RV vaccine, the second generation of RV vaccines successfully completed large clinical trials and were granted licensure. Currently there are two oral RV vaccines available on the European market. Here we briefly describe the main characteristics of both vaccines. Details on the vaccines are available online at the European Medicine Agency (EMA; http://www.ema.europa.eu/).

\subsection{Monovalent human RV vaccine (Rotarix $\left.{ }^{\circledR}, \mathrm{RX}\right)$}

RX (GlaxoSmithKline Biologicals) is an oral, live-attenuated, monovalent G1P [8] human RV vaccine derived from the naturally circulating G1P[8] RV strain 89-
12 , isolated from the stool of a 15-month old child with RV diarrhoea in 1988 [82]. The parental virus was passaged in African green monkey kidney cells, plaquepurified and renamed RIX 4414 [83]. RX was approved for the European market in February 2006 [84]. The licensed vaccine is prepared as a lyophilized powder to be reconstituted with $1 \mathrm{ml}$ of solvent. Each $1.5 \mathrm{ml}$ vaccine dose contains $\geq 10^{6} \mathrm{CCID}_{50}$ (cell culture infectious dose 50\%) of the parent RV strain. Two oral vaccine doses, given at least 4 weeks apart, are necessary for a complete vaccination series. The first dose should be administered as soon as possible after the age of 6 weeks. The vaccination series should be completed preferably before 16 weeks of age, and not later than 24 weeks of age.

\subsection{Pentavalent human-bovine reassortant $\mathrm{RV}$ vaccine (RotaTeq $\left.{ }^{\circledR}, \mathrm{RQ}\right)$}

RQ (Merck \& Co) is a live, oral RV vaccine that contains five reassortant RVs developed from human and bovine parent strains. Four reassortant RVs express one of the outer capsid proteins (G1, G2, G3, G4) from the human parental strain and the attachment protein from the bovine RV strain. The fifth reassortant virus expresses the attachment protein P1[8] from the human RV parental strain and the outer capsid protein (G6) from the bovine RV parental strain. The parental bovine RV strain WC3 (G6,P7[5]) was isolated in 1981 from a calf with diarrhoea and passaged in African green monkey cells [85]. The reassortants are propagated in Vero monkey kidney cells [86]. RQ was licensed for the European market in June 2006 [87]. The licensed vaccine is a ready-to-use $2 \mathrm{ml}$ solution that contains $\geq 2.0-2.8 \times 10^{6}$ infectious units (IU) per individual dose, depending on reassortant. The vaccination course consists of 3 doses. The first dose may be administered from the age of 6 weeks and not later than after the age of 12 weeks. Doses should be given at least 4 weeks apart. The vaccination series of three doses should be completed preferably by the age of 20-22 weeks, but not later than the age of 32 weeks.

\subsection{Adverse events}

According to the Summary of Product Characteristics, both vaccines can cause the following adverse events (frequencies are reported as: very common $(\geq 1 / 10)$; common $(\geq 1 / 100,<1 / 10)$; uncommon $(\geq 1 / 1000,<1 / 100)$; rare $(\geq 1 / 10000$ $<1 / 1000)$ ): diarrhoea and vomiting (very common or common), pyrexia (very common), irritability (common), upper respiratory tract infections (common), abdominal pain, flatulence (uncommon), haematochezia (uncommon), nasopharyngitis, otitis media (uncommon), rash and urticaria (uncommon or rare), intussusception (rare), bronchospasm (rare).

The absolute and relative risk for intussusception and Kawasaki disease following RV vaccination were subject to a systematic review and results are presented in section 5.4 of this paper.

\subsection{Contamination of RV vaccines with porcine circovirus (PCV)}

In February 2010, genome fragments of a porcine circovirus 1 (PCV-1) were detected in two batches of RX during a study using a new technology for detecting viral genetic material. As a result, the manufacturer initiated tests that confirmed the presence of PCV-DNA in vaccine lots, in the vaccine cell bank, and in the viral starting materials from which the vaccine was derived. It has been shown that PCV material had been present since early stages of product development [88] Subsequently, genome fragments from both PCV-1 and PCV-2 were identified also in the RQ vaccine. The origin of PCV contamination was attributed to the porcine trypsin used during the manufacturing process of the vaccines. PCV are animal viruses infecting pigs. PCV-1 does not cause disease in either animals or humans; however PCV-2 can cause disease in pigs but not in humans. Exposure of humans to PCV is common due to its presence in meat and other food products.

Following a review of the oral vaccines RX and RQ, the EMA's Committee for Medicinal Products for Human Use (CHMP) noted that RV vaccines can contain small amounts of PCV-1 and PCV- 


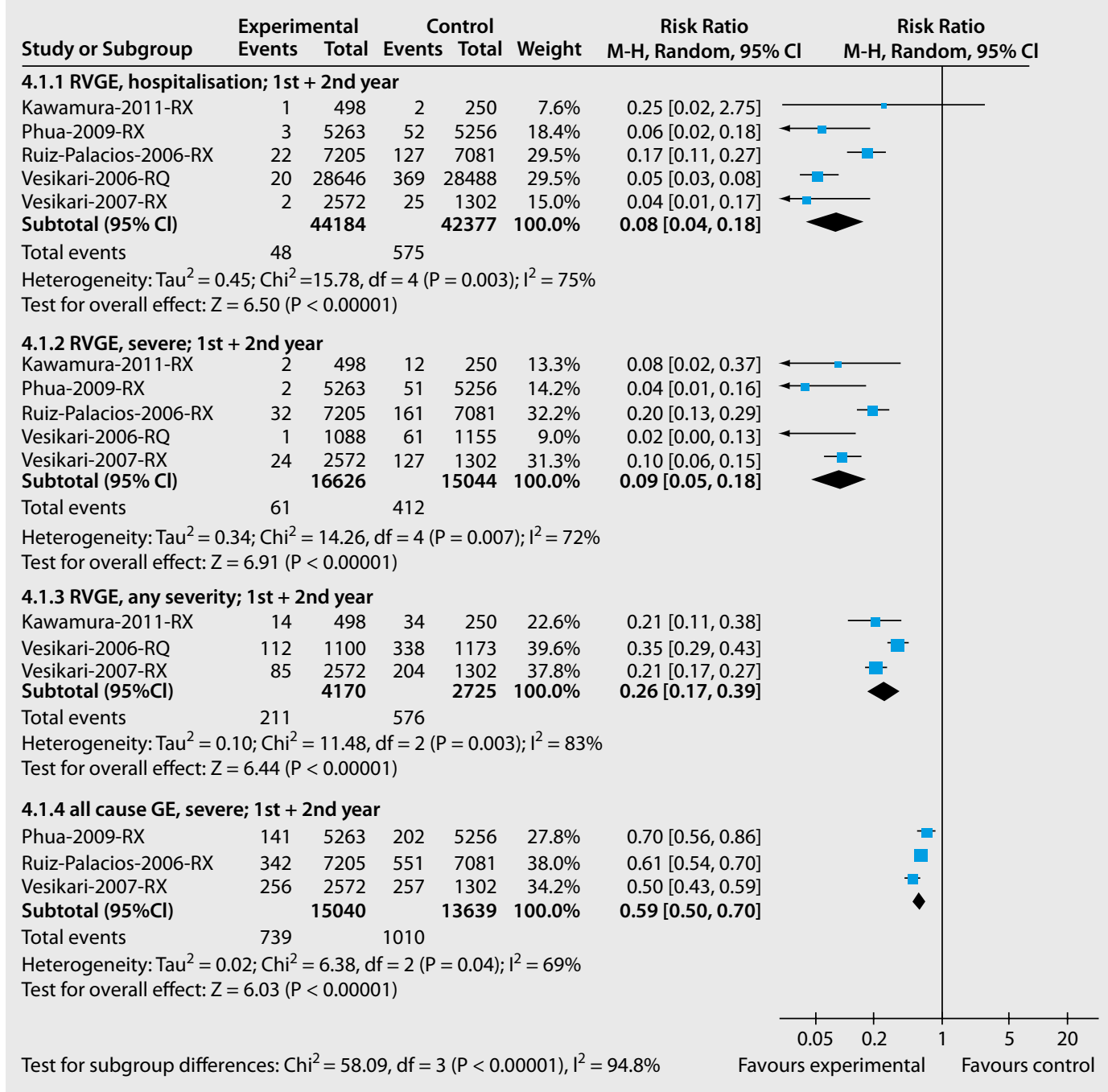

Fig. $3<$ Rotavirus vaccine efficacy compared with placebo against different outcomes over a followup period of 2 years in randomized controlled trials, reported as risk ratio (Mantel-Haenszel random-effects model)
2. Based on the fact that PCV does not cause any disease in humans, the committee concluded that the detection of PCV-1 and PCV-2 did not change the risk-benefit balance of the two vaccines. Since PCV-1 and PCV-2 should not be present in the RV vaccines, manufacturers were instructed to adopt measures to produce the vaccine free of PCV $[89,90]$.

\section{Methodology}

Following the SOP for the development of evidence-based recommendations on immunization of STIKO [91], a working group (WG) on RV vaccination was established in February 2011 and conducted the systematic review and grading of the quality of evidence for vaccine efficacy (VE) and vaccine safety. Reduction in the number of $R V$ infections requiring hospital admission in children $<5$ years of age was defined by the STIKO as the primary goal of adopting routine RV vaccination into the national immunization schedule in Germany.

Following the GRADE (Grading of Recommendations Assessment, Development and Evaluation) methodology, the WG identified several patient-relevant outcomes, which were classified according to a 9-point scale into those that are critical (7-9 points), important (46 points), or of limited importance (13 points) for decision-making [92]. Systematic reviews and meta-analyses were conducted for the efficacy and safety of $\mathrm{RV}$ vaccines with regard to each of these outcomes, considering children aged $<5$ years, vaccinated with one of the two licensed RV vaccines, and compared to children with no RV vaccination. We searched published literature in MEDLINE, EMBASE, BIOSIS, SciSearch, Co- chrane Central Register of Controlled Trials and the Cochrane Database of Systematic Reviews to identify relevant studies. Details on the search strategy, in- and exclusion criteria, and study selection are summarized in Appendix I. An EndNote database was created and completed with references identified in all search strategies. Two reviewers independently screened the title and abstract of each EndNote record and excluded obviously irrelevant reports (1st screening). Based on specific inclusion and exclusion criteria that took into consideration the population, intervention, comparator and the outcome of interest (Appendix I; Tab. 3), a 2nd screening was performed. For the 2nd screening the full text of eligible publications was assessed and appraised independently by two reviewers. Divergent appraisals of studies were discussed with members of the STIKO WG for methods, 
Tab. 1 Vaccine efficacy (VE) of RotaTeq ${ }^{\circledR}(R Q)$ against rotavirus gastroenteritis (RVGE) of different severity and caused by different serotypes

after completion of vaccination

\begin{tabular}{|c|c|c|c|c|c|c|c|c|}
\hline Serotype & Follow-up & Study & Vaccine & & Placebo & & $\%$ VE & $95 \% \mathrm{Cl}$ \\
\hline & & & Events & Participants & Events & Participants & & \\
\hline \multicolumn{9}{|c|}{ RVGE, any severity } \\
\hline \multicolumn{9}{|c|}{ G1 } \\
\hline & 1 year & $\begin{array}{l}\text { Vesikari-2006- } \\
\text { RQ }\end{array}$ & 72 & 2834 & 286 & 2839 & 74.9 & $67.3-80.9$ \\
\hline \multicolumn{9}{|l|}{ G2 } \\
\hline & 1 year & $\begin{array}{l}\text { Vesikari-2006- } \\
\text { RQ }\end{array}$ & 6 & 2834 & 17 & 2839 & 63.4 & $2.6-88.2$ \\
\hline \multicolumn{9}{|l|}{ G3 } \\
\hline & 1 year & $\begin{array}{l}\text { Vesikari-2006- } \\
\text { RQ }\end{array}$ & 1 & 2834 & 6 & 2839 & 82.7 & $<0-99.6$ \\
\hline \multicolumn{9}{|l|}{ G4 } \\
\hline & 1 year & $\begin{array}{l}\text { Vesikari-2006- } \\
\text { RQ }\end{array}$ & 3 & 2834 & 6 & 2839 & 48.1 & $<0-91.6$ \\
\hline \multicolumn{9}{|l|}{ G9 } \\
\hline & 1 year & $\begin{array}{l}\text { Vesikari-2006- } \\
\text { RQ }\end{array}$ & 1 & 2834 & 3 & 2839 & 65.4 & $<0-99.3$ \\
\hline \multicolumn{9}{|c|}{ Hospitalization/ED visits } \\
\hline \multicolumn{9}{|c|}{ G1 } \\
\hline & 1 year & $\begin{array}{l}\text { Vesikari-2006- } \\
\text { RQ }\end{array}$ & 16 & 34,035 & 328 & 34,003 & 95.1 & $91.6-97.1$ \\
\hline & 2 years & $\begin{array}{l}\text { Vesikari-2006- } \\
\text { RQ }\end{array}$ & 14 & 14,018 & 272 & 13,983 & 94.8 & $91.2-97.2$ \\
\hline \multicolumn{9}{|l|}{ G2 } \\
\hline & 1 year & $\begin{array}{l}\text { Vesikari-2006- } \\
\text { RQ }\end{array}$ & 1 & 34,035 & 8 & 34,003 & 87.6 & $<0-98.5$ \\
\hline & 2 years & $\begin{array}{l}\text { Vesikari-2006- } \\
\text { RQ }\end{array}$ & 0 & 14,014 & 1 & 13,968 & 100.0 & $<0-100$ \\
\hline \multicolumn{9}{|l|}{ G3 } \\
\hline & 1 year & $\begin{array}{l}\text { Vesikari-2006- } \\
\text { RQ }\end{array}$ & 1 & 34,035 & 15 & 34,003 & 93.4 & $49.4-99.1$ \\
\hline & 2 years & $\begin{array}{l}\text { Vesikari-2006- } \\
\text { RQ }\end{array}$ & 0 & 14,014 & 12 & 13,968 & 100.0 & $64.0-100$ \\
\hline \multicolumn{9}{|l|}{ G4 } \\
\hline & 1 year & $\begin{array}{l}\text { Vesikari-2006- } \\
\text { RQ }\end{array}$ & 2 & 34,035 & 18 & 34,003 & 89.1 & $52.0-97.5$ \\
\hline & 2 years & $\begin{array}{l}\text { Vesikari-2006- } \\
\text { RQ }\end{array}$ & 2 & 14,014 & 16 & 13,969 & 87.5 & $46.8-98.6$ \\
\hline \multicolumn{9}{|l|}{ G9 } \\
\hline & 1 year & $\begin{array}{l}\text { Vesikari-2006- } \\
\text { RQ }\end{array}$ & 0 & 34,035 & 13 & 34,003 & 100.0 & $67.4-100.0$ \\
\hline & 2 years & $\begin{array}{l}\text { Vesikari-2006- } \\
\text { RQ }\end{array}$ & 0 & 14,029 & 13 & 13,963 & 100.0 & $67.0-100$ \\
\hline
\end{tabular}

and a decision on study inclusion was made jointly.

\section{Data extraction and statistical analyses}

Data were extracted independently using a standardized extraction form. For each included study, information on study design, participants, sampling and group allocation, intervention, outcomes, study results and risk of bias was systematically extracted. If available, study registries were screened for additional data that were not presented in the selected publications (http://www.gsk-clinicalstudyregister.com/; http://clinicaltrials.gov). Characteristics of each included study are summarized in the Appendix II. All outcomes were dichotomous (occurrence of the event or not). The to- tal number of participants and the number of participants that experienced the event were extracted for all studies. Extracted data were entered into the computer software Review Manager (version 5.1, Nordic Cochrane Centre, Copenhagen, Denmark).

We calculated fixed effects as well as random effects models to obtain pooled estimates. To account for heterogene- 


\section{Tätigkeitsberichte}

Tab. 2 Vaccine efficacy (VE) of Rotarix ${ }^{\circledR}(R X)$ against rotavirus gastroenteritis (RVGE) of different severity and caused by different serotypes after completion of vaccination

\begin{tabular}{|c|c|c|c|c|c|c|c|c|}
\hline Serotype & Follow-up & Study & Vaccine & & Placebo & & $\%$ VE & $95 \% \mathrm{Cl}$ \\
\hline & & & Events & Participants & Events & Participants & & \\
\hline \multicolumn{9}{|c|}{ RVGE, any severity } \\
\hline \multicolumn{9}{|c|}{ G1 } \\
\hline & 1 year & $\begin{array}{l}\text { Vesikari-2007- } \\
\text { RX }\end{array}$ & 4 & 2572 & 46 & 1302 & 95.6 & $87.9-98.8$ \\
\hline & 2 years & $\begin{array}{l}\text { Vesikari-2007- } \\
\text { RX }\end{array}$ & 18 & 2572 & 89 & 1302 & 89.8 & $82.9-94.2$ \\
\hline & 2 years & $\begin{array}{l}\text { Kawamura- } \\
\text { 2011-RX }\end{array}$ & 4 & 498 & 13 & 250 & 84.6 & $50.0-96.3$ \\
\hline \multicolumn{9}{|l|}{ G2 } \\
\hline & 1 year & $\begin{array}{l}\text { Vesikari-2007- } \\
\text { RX }\end{array}$ & 3 & 2572 & 4 & 1302 & 62.0 & $<0-94.4$ \\
\hline & 2 years & $\begin{array}{l}\text { Vesikari-2007- } \\
\text { RX }\end{array}$ & 14 & 2572 & 17 & 1302 & 58.3 & $10.1-81.1$ \\
\hline & 2 years & $\begin{array}{l}\text { Kawamura- } \\
\text { 2011-RX }\end{array}$ & 1 & 498 & 2 & 250 & 74.9 & -382.2 to 99.6 \\
\hline \multicolumn{9}{|l|}{ G3 } \\
\hline & 1 year & $\begin{array}{l}\text { Vesikari-2007- } \\
\text { RX }\end{array}$ & 1 & 2572 & 5 & 1302 & 89.9 & $9.5-99.8$ \\
\hline & 2 years & $\begin{array}{l}\text { Vesikari-2007- } \\
\text { RX }\end{array}$ & 3 & 2572 & 10 & 1302 & 84.8 & $41.0-97.3$ \\
\hline & 2 years & $\begin{array}{l}\text { Kawamura- } \\
\text { 2011-RX }\end{array}$ & 3 & 498 & 13 & 250 & 88.4 & $57.8-97.9$ \\
\hline \multicolumn{9}{|l|}{ G4 } \\
\hline & 1 year & $\begin{array}{l}\text { Vesikari-2007- } \\
\text { RX }\end{array}$ & 3 & 2572 & 13 & 1302 & 88.3 & $57.5-97.9$ \\
\hline & 2 years & $\begin{array}{l}\text { Vesikari-2007- } \\
\text { RX }\end{array}$ & 6 & 2572 & 18 & 1302 & 83.1 & $55.6-94.5$ \\
\hline & 2 years & $\begin{array}{l}\text { Kawamura- } \\
\text { 2011-RX }\end{array}$ & 1 & 498 & 1 & 250 & 49.8 & -384.6 to 99.4 \\
\hline \multicolumn{9}{|l|}{ G9 } \\
\hline & 1 year & $\begin{array}{l}\text { Vesikari-2007- } \\
\text { RX }\end{array}$ & 13 & 2572 & 27 & 1302 & 75.6 & $51.1-88.5$ \\
\hline & 2 years & $\begin{array}{l}\text { Vesikari-2007- } \\
\text { RX }\end{array}$ & 38 & 2572 & 71 & 1302 & 72.9 & $59.3-82.2$ \\
\hline & 2 years & $\begin{array}{l}\text { Kawamura- } \\
\text { 2011-RX }\end{array}$ & 5 & 498 & 5 & 250 & 49.8 & -118.1 to 88.4 \\
\hline \multicolumn{9}{|c|}{ RVGE, severe } \\
\hline \multicolumn{9}{|l|}{ G1 } \\
\hline & 1 year & $\begin{array}{l}\text { Ruiz-Palacios- } \\
\text { 2006-RX }\end{array}$ & 3 & 9009 & 32 & 8858 & 90.8 & $70.5-98.2$ \\
\hline & 1 year & $\begin{array}{l}\text { Vesikari-2007- } \\
\text { RX }\end{array}$ & 2 & 2572 & 28 & 1302 & 96.4 & $85.7-99.6$ \\
\hline & 2 years & $\begin{array}{l}\text { Ruiz-Palacios- } \\
\text { 2006-RX }\end{array}$ & 9 & 7205 & 51 & 7081 & 82.7 & $64.4-92.5$ \\
\hline & 2 years & Phua-2009-RX & 0 & 5263 & 21 & 5256 & 100.0 & $80.8-100.0$ \\
\hline & 2 years & $\begin{array}{l}\text { Vesikari-2007- } \\
\text { RX }\end{array}$ & 4 & 2572 & 57 & 1302 & 96.4 & $90.4-99.1$ \\
\hline & 2 years & $\begin{array}{l}\text { Kawamura- } \\
\text { 2011-RX }\end{array}$ & 1 & 498 & 6 & 250 & 91.6 & $31.0-99.8$ \\
\hline \multicolumn{9}{|l|}{ G2 } \\
\hline & 1 year & $\begin{array}{l}\text { Ruiz-Palacios- } \\
\text { 2006-RX }\end{array}$ & 5 & 9009 & 9 & 8858 & 45.4 & -81.5 to 85.6 \\
\hline
\end{tabular}


Tab. 2 Vaccine efficacy $(V E)$ of Rotarix ${ }^{\circledR}(R X)$ against rotavirus gastroenteritis (RVGE) of different severity and caused by different serotypes after completion of vaccination (Continued)

\begin{tabular}{|c|c|c|c|c|c|c|c|c|}
\hline Serotype & Follow-up & Study & Vaccine & & Placebo & & $\%$ VE & $95 \% \mathrm{Cl}$ \\
\hline & & & Events & Participants & Events & Participants & & \\
\hline & 1 year & $\begin{array}{l}\text { Vesikari-2007- } \\
\text { RX }\end{array}$ & 1 & 2572 & 2 & 1302 & 74.7 & $<0-99.6$ \\
\hline & 2 years & $\begin{array}{l}\text { Vesikari-2007- } \\
\text { RX }\end{array}$ & 2 & 2572 & 7 & 1302 & 85.5 & $24.0-98.5$ \\
\hline & 2 years & Phua-2009-RX & 0 & 5263 & 2 & 5256 & 100.0 & $<0-100.0$ \\
\hline \multicolumn{9}{|l|}{ G3 } \\
\hline & 1 year & $\begin{array}{l}\text { Vesikari-2007- } \\
\text { RX }\end{array}$ & 0 & 2572 & 5 & 1302 & 100.0 & $44.8-100.0$ \\
\hline & 2 years & $\begin{array}{l}\text { Vesikari-2007- } \\
\text { RX }\end{array}$ & 1 & 2572 & 8 & 1302 & 93.7 & $52.8-99.9$ \\
\hline & 2 years & $\begin{array}{l}\text { Kawamura- } \\
\text { 2011-RX }\end{array}$ & 0 & 498 & 4 & 250 & 100.0 & $24.0-100.0$ \\
\hline & 2 years & Phua-2009-RX & 1 & 5263 & 18 & 5256 & 94.5 & $64.9-99.9$ \\
\hline \multicolumn{9}{|l|}{ G4 } \\
\hline & 1 year & $\begin{array}{l}\text { Vesikari-2007- } \\
\text { RX }\end{array}$ & 0 & 2572 & 7 & 1302 & 100.0 & $64.9-100.0$ \\
\hline & 2 years & $\begin{array}{l}\text { Vesikari-2007- } \\
\text { RX }\end{array}$ & 1 & 2572 & 11 & 1302 & 95.4 & $68.3-99.9$ \\
\hline \multicolumn{9}{|l|}{ G9 } \\
\hline & 1 year & $\begin{array}{l}\text { Vesikari-2007- } \\
\text { RX }\end{array}$ & 2 & 2572 & 19 & 1302 & 94.7 & 77.9-99.4 \\
\hline & 2 years & $\begin{array}{l}\text { Vesikari-2007- } \\
\text { RX }\end{array}$ & 13 & 2572 & 44 & 1302 & 85.0 & $71.7-92.6$ \\
\hline & 2 years & $\begin{array}{l}\text { Kawamura- } \\
\text { 2011-RX }\end{array}$ & 1 & 498 & 2 & 250 & 74.9 & -382.2 to 99.6 \\
\hline & 2 years & Phua-2009-RX & 1 & 5263 & 12 & 5256 & 91.7 & $43.8-99.8$ \\
\hline
\end{tabular}

ity, we decided to present the results of the random effects model in the following. However, results obtained by using the fixed effects model were very similar (data not shown). We analysed dichotomous data by calculating MantelHaenszel random effects risk ratios (RR) or odds ratios (OR) and corresponding $95 \%$ confidence intervals $(95 \% \mathrm{CI})$ for $\mathrm{RV}$ vaccine recipients versus placebo recipients of each included trial. The pooled $\mathrm{RR}$ and $\mathrm{OR}$ were used to establish pooled vaccine efficacy (VE) or risk for vaccine adverse effects according to the following formula: (1-risk/odds ratio) $\times 100$. Judgement of the extent of heterogeneity was based on similarity of point estimates, extent of overlap of confidence intervals, and statistical criteria including tests of heterogeneity and $\mathrm{I}^{2}$ [93]. On the basis of the VE we calculated the number needed to vaccinate (NNV) for selected outcomes as the inverse of the absolute risk reduction (1/CER-EER) (CER $=$ control event rate; EER $=$ experimental group event rate). Potential publication bias was assessed by visual inspection of funnel plots (Appendix V).

\section{Grading the quality of evidence}

Pooled data with respect to all critical and important outcomes derived from the meta-analyses of the included studies were imported into the computer software GRADEprofiler (version 3.6, GRADE working group). The quality of evidence across studies for each critical and important outcome was judged based on specific criteria such as study design, risk of bias, consistency, directness, precision and further criteria as suggested by GRADE [94]. With the help of the software, a GRADE evidence profile was created, indicating the number of studies, the study design, number of participants and events in the vaccine and placebo group, the relative and absolute risks as well as the WG's judgements for the quality of evidence and the importance of the outcome for each outcome (see - Tab. 3). The overall quality of evidence was judged across outcomes based on the lowest quality of evidence for any of the critical outcomes.

\subsection{Methodology for the evaluation of RV vaccine efficacy}

RV VE was defined as the relative reduction in RV gastroenteritis (RVGE) risk for specified endpoints after vaccination as established by a randomized placebo-controlled trial (RCT). We used the search terms "rotavirus", "vaccine", "immunization" and "randomized controlled trial" to identify studies examining the efficacy of RV vaccines in children. The search strategy and flow chart of the literature search process are presented in Appendix I (Tab. 2, Fig. 1). Each study that was included in the final analysis was assigned to an acronym consisting of the author of the primary publication, year of publication and vaccine brand tested. 


\section{Inclusion and exclusion criteria}

We included RCTs published between January 2004 and September 2011 if efficacy of either RX or RQ on at least one the predefined patient-relevant outcomes was reported for healthy children $<5$ years of age from industrialized or newly industrialized countries (Europe, Australia, Canada, USA, Latin America and Asia). RCTs were excluded if a vaccine formulation was used that was different from the products licensed in Europe, if the vaccination series was incomplete, if the vaccination schedule differed from the approved schedule, or if oral poliovirus vaccine (OPV) was co-administered with the $\mathrm{RV}$ vaccine. Clinical trials with OPV co-administration were excluded as concomitant administration of $R V$ vaccines and OPV might slightly reduce the immune response to $\mathrm{RV}$ vaccines, and as only inactivated poliovirus vaccines (but not OPV) are recommended for the use in Germany $([95,96,97]$, Appendix I, Tab. 3).

\section{Outcomes}

According to the judgement of the WG, the following outcomes were regarded as "critical" or "important", and VE against these outcomes was extracted from the included RCTs: (1) RVGE requiring hospitalization; (2) severe RVGE (as defined by severity-score in the trial report); (3) death due to RVGE; (4) nosocomial RVGE; (5) severe AGE; and (6) RVGE of any severity (Appendix I, Tab. 1). For the assessment of GE severity the 20-point Vesikari scale was used in RX trials; a score $>11$ was considered as severe disease [34]. In RQ trials the 24-point Clark scale was used designating a score $>16$ as severe disease $[34,98]$.

\section{Analysis}

In a first step, a meta-analysis for every single outcome was performed for each $\mathrm{RV}$ vaccine. This included estimates for different observation periods (i.e. single years: 1st, 2nd or 3rd year; follow up-periods: 1 st +2 nd or 1 st -3 rd year post vaccination). Data from both, per-protocol and intention-to-treat analyses were extracted, if available. In a second step, data for both vaccines were pooled, as the objective of this review was to evaluate the efficacy of RV vaccination but not of a specific vaccine product. For this purpose only per-protocol results were used since this approach included the largest number of studies for the predefined outcomes. The results from single studies and from the meta-analysis of pooled data of all outcomes and all observation periods are listed in Appendix IV. In the final evidence profile, only pooled data of both vaccines for the two-year follow-up period were presented.

\subsection{Methodology for the evaluation of RV vaccine effectiveness and impact based on observational studies}

$R V$ vaccine effectiveness was defined as the relative reduction in RVGE risk for specified endpoints with regard to the RV vaccination status of study subjects based on OR in case-control studies and RR in cohort studies. In addition, we aimed to identify impact studies which assessed the effects of RV vaccination at population level, including herd protection, reduction in the number of nosocomial infections and a potential replacement of RV genotype strains. These effects cannot be assessed or are difficult to assess in RCTs. Search terms "rotavirus", "vaccine", "immunization", "vaccine effectiveness" and "impact" were used to identify studies which examined the effectiveness of RV vaccines or which reported on the epidemiological impact of RV vaccination. The search strategy and flow chart of the literature search process are presented in Appendix I (Tab. 4, Fig. 2). Each study that was included in the final analysis was assigned an acronym consisting of the author of the primary publication, year of publication and vaccine brand used in the respective population.

\section{Inclusion and exclusion criteria}

We included case-control, cohort, and impact studies which were published between July 2008 and February 2012 if the effect of the licensed RV vaccines on at least one of the predefined patientrelevant outcomes was reported concerning healthy children $<5$ years of age from industrialized or newly industrialized countries (Europe, Australia, Cana- da, USA, Latin America and Asia). Observational studies were excluded if OPV was co-administered with the RV vaccine, if the majority of study subjects had another ethnicity than Caucasian or Hispanic, or if the objective of the study did not ask for predefined patient-relevant outcomes.

\section{Outcomes}

The same patient-relevant outcomes were considered as for vaccine efficacy (see outcomes in section 4.1).

\section{Analysis}

A meta-analysis of effectiveness data of included case-control studies was performed on basis of crude OR and adjusted OR and with regard to RV vaccination status (both one dose, and at least two doses). Of the selected cohort studies, crude effectiveness data for preventing RVGE and all-cause AGE were included in a meta-analysis. Only pooled data for both licensed RV vaccines were considered for the meta-analysis. The results of single studies and of the meta-analysis of pooled data of all outcomes are listed in Appendix IV.

Except for the effectiveness to prevent nosocomial RVGE, results of the impact studies were not appropriate for a metaanalysis since no uniform effect estimator was reported. Therefore we conducted a descriptive analysis. Study data are listed in Appendix III.

\subsection{Methodology of the evaluation of RV vaccine safety}

Since a recently published systematic review was available and provided high quality and sufficient information on all relevant safety outcomes, results from this review were used [99]. The review was published in 2010 by the Cochrane Collaboration group and evaluated the efficacy and safety of both RX and RQ as observed in published RCTs from February 1998 to May 2010. Data were extracted from the systematic review and included in the meta-analysis. In a second step, data from RCTs published from May 2010 until December 2011 and identified in the search concerning efficacy (see above) were added. In addition an evaluation of 
data derived from post-marketing observational studies was performed to better assess extremely rare adverse events (i.e. intussusception and Kawasaki disease). To identify observational studies examining the risk of intussusception after RV vaccination, a systematic literature was performed using a combination of the search terms "rotavirus", "vaccine", "immunization" and "intussusception", and the methodology described above. The search strategy and flow chart of the literature search process are presented in Appendix I (Tab. 5, Fig. 3).

\section{Inclusion and exclusion criteria}

Studies from any part of the world were included in our assessment, since it was regarded important to assess the evidence on the safety of RV vaccines irrespective of the study location. Furthermore, we considered that - in contrast to VE-indirectness due to a study setting in a developing country plays a less important role when regarding safety issues.

\section{Outcomes}

For the evaluation of RV vaccine safety, the WG identified the following patientrelevant outcomes as important or critical: (1) vaccine-induced intussusception; (2) Kawasaki disease; and (3) reactogenicity of the vaccine as indicated by diarrhoea, vomiting or fever (Appendix I, Tab. 1). All outcomes were included in the final evidence profile.

\section{Analysis}

The observation period for serious adverse events as Kawasaki disease and intussusception varied largely in randomized controlled trials. Time periods observed ranged from 30 days to 1 year after each dose. Irrespective of the observation period, considered data for both vaccines were pooled in a meta-analysis (Appendix IV). In addition, data from two large trials with an extra focus on the risk of intussusception were reported in detail. In these studies, intussusception was defined as a safety outcome in the study protocol. Adverse events of special interest were monitored for a time period of up 30 days after each dose in the RX study, and for up to 42 days in the RQ study [100, 101]. Results of the ob- servational studies concerning the risk of intussusception did not permit a meta-analysis because of different study designs and different baseline risks. We therefore conducted a descriptive analysis. Relevant study data of included studies are listed in Appendix III (Tab. 7).In most safety studies, for each type of solicited symptoms regarding reactogenicity (vomiting, fever, diarrhoea), occurrence of the symptoms was documented for follow-up periods varying between $0-7$ days to $0-14$ days post vaccination after each dose. As the results did not show major differences, we decided to pool only data for the time period after the 1st dose for each symptom (Appendix IV).

\section{Results of the systematic reviews and quality assessments}

\subsection{Ranking of patient-relevant outcomes}

The following patient-relevant outcomes were ranked as important or critical in respect to VE: (1) RV-related hospitalization; (2) severe RVGE (as defined by severity score in the study reports); (3) RVrelated deaths; (4) nosocomial RVGE; (5) severe all-cause GE; and (6) RVGE of any severity. For the evaluation of RV vaccine safety the following outcomes were regarded as critical or important harms: (7) intussusception; (8) Kawasaki disease; and (9) reactogenicity of the vaccine as indicated by diarrhoea, vomiting or fever.

After completion of the systematic literature reviews on all outcomes, a reranking was performed. In the final ranking, risk for intussusception as well as efficacy in preventing RV-related hospitalization and severe RVGE were ranked as critical, while the other outcomes were ranked as important (Appendix I, Tab. 1).

\subsection{Efficacy of RV vaccines}

\section{Description and assessment of the quality of included studies}

We identified 479 references in the first screening, of which 51 were eligible for the second screening. Of these, six independent studies were included in the final assessment of VE: four assessed RX and two RQ VE. The flow chart for study selection and the study characteristics of included studies is shown in Appendix I (Tab. 2, Fig. 1).

All included studies were RCTs using parallel-group design and comparing a $R V$ vaccine with placebo $[100,101,102$, $103,104,105]$. A total 107,249 participants were enrolled in the six trials; four RX trials included 35,636 and the two RQ trials 71,613 participants. RX and RQ studies were conducted between 2003 and 2009 in Europe, Latin America and Asia and between 2001 and 2005 in Europe, USA, Latin America and Asia, respectively. All RX trials were sponsored by GlaxoSmithKline Biologicals and all RQ trials by Merck \& Co., Inc.

Only healthy infants aged 6-14 weeks were enrolled. The 1st vaccine doses were predominantly administered at 6-14 weeks of age, and subsequent doses were given 4-8 weeks apart. Routine childhood vaccines were administered concomitantly. The duration of follow up after vaccination varied between 1 and 3 years.

Each trial provided information on at least one outcome that was relevant for this review (Appendix IV). No data were available for the efficacy of either vaccine to prevent nosocomial RVGE or to reduce RV mortality. A detailed risk of bias assessment regarding adequate sequence generation, allocation concealment, blinding, missing output data, selective reporting and other reasons for bias was carried out for each trial and is shown in Appendix II (study characteristics). In summary, all RX trials and one RQ trial had a low risk of bias for three or more criteria; one RQ trial had missing information on sequence generation and allocation concealment.

\section{Results}

The pooled random-effects model with regard to VE in the first 2 years after vaccination showed a relative risk reduction [RRR] of 92\% (95\%CI 82-96) for RVGE requiring hospitalization, $91 \%$ (95\% CI 82 95) for severe RVGE, 74\% (95\%CI 61-83) for RVGE of any severity and $41 \%(95 \% \mathrm{CI}$ 30-50) for AGE. Except for results of one trial on efficacy against RVGE hospitalization [102], efficacy data of both, single 
studies and pooled analyses, were statistically significant ( Fig. 3). The respective NNV for the outcomes named above were 80 infants (absolute risk reduction [ARR] $0.0125,95 \%$ CI $0.0114-0.0137$ ) to be vaccinated to prevent one $\mathrm{RV}$ associated hospitalization, 42 (ARR $0.0237,95 \% \mathrm{CI}$ 0.0210-0.0266) to prevent a severe RVGE, six (ARR 0.160 , 95\%CI $0.1435-0.1776$ ) to prevent a RVGE of any severity and 40 (ARR 0.0249 , 95\%CI 0.0193-0.0305) to prevent a severe AGE. The pooled data showed a high grade of heterogeneity for each predefined outcome with $\mathrm{I}^{2}$ ranging from $69-83 \%$. Variability was substantial, but all effects were pointing clearly in the same direction [106]. No evidence of publication bias was detected for any of the outcomes (Appendix V, Fig. 1, Fig. 2, Fig. 3, Fig. 4).

\section{Conclusion}

The identified studies consistently demonstrated a high RV vaccine efficacy against outcomes rated as important or critical. The overall quality of evidence derived from the included studies is high. The high level of heterogeneity is worth mentioning; however, as all study results were pointing in the same direction with overlapping confidence intervals favouring vaccination, the pooled analysis was considered acceptable and heterogeneity not an obstacle to decision-making.

\section{Efficacy of RX and RQ against different RV genotypes}

The genotype-specific efficacy of RX and RQ against RVGE of different degrees of severity had been evaluated in phase III randomized controlled trials $[100,102$, $103,104,107,108]$. Here, the results are presented briefly:

Genotype-specific efficacy of RQ vaccine. RQ was designed to prevent RVGE caused by the genotypes contained in the vaccine (G1, G2, G3, G4). Protective efficacy of $R Q$ against specific $G$ genotypes (G1-G4 and G9) was measured as reduction of the RVGE incidence of any severity, and as reduction in the rate of hospitalizations and emergency department visits due to RVGE that occurred at least 14 days after the 3rd dose of vaccine in the 1st RV season following vaccination (• Tab. 1).
With regard to the reduction of hospitalizations and ED visits, RQ efficacy data were also presented for the 2nd year after vaccination. Results for VE in the 2nd year were comparable to those of the 1 st year. However, the numbers of events observed-especially for non-G1 genotypes-were small, resulting in large CIs and non-significant results for G2, G3, G4 and G9. Due to the very low incidence of RVGE caused by non-G1 genotypes observed during the clinical trials, further research is needed to ascertain the efficacy of $R Q$ against all rare genotypes.

\section{Genotype-specific efficacy of RX vac-} cine. $\mathrm{RX}$ is a monovalent vaccine and contains only G1P[8]. Cross-protection against infection due to non-G1 genotypes was expected because $\mathrm{P}[8]$ is shared by most other circulating $\mathrm{RV}$ strains and protection is also associated with VP2 and VP6 and non-structural proteins. Protective efficacy of RX against specific G genotypes (G1-G4) was measured as reduction in the incidence of severe RVGE (i.e. Vesicari score $\geq 11$ ) as well as RVGE of any severity occurring at least 14 days after the 2 nd dose of vaccination, during the 1st and 2 nd year of life (• Tab. 2). VE against severe RVGE caused by non-G1 strains showed considerable variation, ranging from 45 to $100 \%$ during the 1st year and from 75 to $100 \%$ during the 2 nd year after vaccination. Efficacy estimates for G2, G3, G4 and G9 showed broad CIs, but were statistically significant for all except G2-serotypes [100, 107, 109]. Data from a small Asian trial showed non-significant results for G4 and G9 as well [102]. Due to the small numbers of participants with RVGE caused by non-G1 genotypes observed during the clinical trials, further research is needed to clearly establish the efficacy of RX against all rare genotypes.

\subsection{Effectiveness and impact of RV vaccines}

\section{Description of studies}

In contrast to VE, which is usually assessed in RCTs by administering vaccines and observing outcomes under controlled conditions in a cohort of healthy participants, vaccine effectiveness and impact of vaccination are assessed in the general or the target population after the vaccine went into widespread use. While vaccine effectiveness is a measure of direct vaccine protection for the vaccinated as compared to non-vaccinated individuals, impact of vaccination includes direct and indirect effects at population level and depends-among other variables-on the vaccination coverage. Despite methodological limitations due to their study design, observational studies and ecological studies can add important evidence on the effects of the vaccine, e.g. on rare outcomes (such as RV-related death), outcomes difficult to measure in RCTs (such as nosocomial infections), or population-level effects (such as herd protection). Of 469 potentially eligible articles identified in a database search, we identified 8 case-control studies, 5 cohort studies and 22 impact studies to be included in the final analysis (Appendix I, Tab. 4, Fig. 2). Detailed study characteristics are reported in Appendix III (Tab. 1: cases-control studies, Tab. 2: cohort studies, Tab. 3, Tab. 4, Tab. 5, Tab. 6: impact studies).

\section{Case-control studies}

Of eight included case-control studies, five were conducted in the US where RQ was predominantly used, two were performed in Spain, and one in Israel where both $\mathrm{RV}$ vaccines were administered $[110,111,112,113,114,115,116,117]$ (Appendix III, Tab. 1). The following outcomes were considered: RVGE requiring hospitalization and/or an emergency department (ED) visit (knowing that the majority of $E D$ visits resulted in hospitalization) and RVGE of any severity in outpatients (this outcome was only featured in Spanish studies). In six of eight studies, cases and controls were matched for age and $\mathrm{RV}$ seasonality. In all included studies except one, adjusted ORs and/or vaccine effectiveness were reported. Effect measures were mostly controlled for the following potential confounders: age, seasonality, study site, and in some studies also for gender, race/ethnicity, insurance status, and socioeconomic status. Only in one study was the analysis controlled for breastfeeding, attendance of a daycare fa- 
cility, siblings, preterm birth, underlying diseases, and tobacco smoke exposure. In all studies but one, ORs and/or vaccine effectiveness were reported for fully or partially vaccinated children. The range of median and mean age, respectively, of case patients was 9-17 months. Studies were conducted between 2006 and 2011 and included mostly 2-3 RV seasons. Overall, 1566 cases and 11,700 controls were included in the eight studies.

Four studies used one control group while the four remaining studies had two control groups. Control subjects were defined as children with RV negative AGE leading to hospitalization ( $\mathrm{n}=6$ studies), children with acute respiratory infection leading to hospitalization $(n=2)$, children from an immunization information system (IIS) $(n=2)$, children who were hospitalized for other reasons than RVGE $(n=1)$ or attended the same medical practice for routine care $(n=1)$.

Although we identified heterogeneity in selection of controls, controlling for possible confounding, study period, and vaccines used, we conducted a meta-analysis of ORs. The forest plot with numbers of cases and controls included in each study, and crude OR for individual studies and from pooled data is shown in - Fig. 4.

Pooled ORs showed that RV vaccination is effective in preventing RVGE requiring hospitalization, based on both adjusted data, and on crude data. A forest plot with adjusted data is presented in Appendix IV, as well as another plot on pooled ORs regarding to RVGE of any severity. After at least two doses of RV vaccine, pooled vaccine effectiveness to prevent RVGE-associated hospitalization was estimated at $84 \%$ (95\%CI 78-88\%), and after one dose $81 \%$ (95\%CI 56-92\%), respectively. Pooled ORs were homogenous and consistent. The $95 \%$ CI were wide only in studies with very small numbers of events.

Conclusion. The effectiveness data assessed in case-control studies confirmed the efficacy data of the RCTs reported above. We can conclude from meta-analyses of case-control studies that RV vaccination proved very effective also under field conditions.

\section{Cohort studies}

A total of five cohort studies were identified after applying the inclusion and exclusion criteria $[116,118,119,120,121]$ (Appendix III, Tab. 2). Of these, two studies were nested in impact studies. Two studies were conducted in the US, one in Australia, one in Israel and one in France. In four studies RQ was used, and in one RX. Data were compiled by active hospital surveillance $(n=2)$, by analysis of hospital admission data $(n=1)$ or health insurance claim data $(\mathrm{n}=2)$. The primary outcomes were prevention of RVGE or all cause AGE leading to hospitalization in non-vaccinated or fully vaccinated children younger than 1 year $(n=2), 2$ years $(n=2)$ or 3 years of age $(n=1)$. In two studies, the risk reduction of all cause AGE in outpatients associated with the use of $\mathrm{RV}$ vaccine was calculated. The following information on study subjects was available: age, RV vaccination and disease status, geographical region and setting. Only the study from Israel stratified its analysis according the children's socioeconomic status. None of the studies was controlled for potential confounding factors. Overall, 141,352 children's health and vaccination status data were included in the cohort studies used to determine vaccine effectiveness. A meta-analysis was conducted although we identified heterogeneity in the source of study subjects, data collection, study period, age of children and vaccine type. Pooled effectiveness to prevent RVGE-associated hospitalization was estimated to be 94\% (95\%CI 81-98\%) (• Fig. 5). Pooled RRs of data on preventing all cause AGE leading to hospitalization and in outpatients, respectively, are reported in Appendix IV.

Conclusion. Pooled data of cohort studies were in line with results of case-control studies and RCTs assessing vaccine efficacy. However, the quality of data reported by Wang et al. were questionable as no case of hospitalized RVGE and only one outpatient case with RVGE were observed in of over 30,000 vaccinated children in two RV seasons. It is also questionable if studies based on health insurance claims and/or ICD-9 or ICD-10 codes are exempt of bias.

\section{Impact studies}

A total of 22 impact studies fulfilled our inclusion criteria (Appendix I; Fig. 1) [78, $118,121,122,123,124,125,126,127,128,129$, $130,131,132,133,134,135,136,137,138,139$, $140,141]$. Of these, five were conducted in Europe, nine in the US, five in Australia, and three in Mexico. In these countries, $\mathrm{RV}$ vaccines became available in 2006 or 2007. In Europe and Australia both vaccines were available on the market; in the US RQ and in Mexico RX were predominantly used. In the majority of studies, the study period lasted 2-3 RV seasons (range 1-4) after introduction of routine $\mathrm{RV}$ vaccination. Only in one study performed in Greece RV vaccination was not included in the national childhood immunization schedule. Age of the examined study population varied: Mostly, data of children under 5 years of age $(\mathrm{n}=11$ studies $)$ or of all ages $(\mathrm{n}=7$ studies) were analysed; in two studies children under 3 and in three studies children under 18 years of age were included. In all studies, data on RVGE and all cause AGE in the "post-vaccination period" were compared with data of the "prevaccination period". Data were collected from hospitals or emergency departments (ED) by screening of admission data; one study included patients from a network of paediatric practices. RV diagnosis was always confirmed by laboratory testing. In five studies, only data on laboratory diagnosis were analysed. Outcome variables were the number or rate of hospitalizations or admissions due to RVGE or all cause AGE, episodes of RVGE, or all cause AGE in outpatients, and total number or rate of laboratory-confirmed RV infections. Information on study participants usually included age, geographic region, study period and RV laboratory test results. In 14 of 22 studies, RV vaccination coverage was reported (range 30-90\%).

Impact on $R V$ disease incidence. All impact studies report a dramatic decrease of RVGE over one or two RV seasons after the introduction of routine RV vaccination in infants; 12 studies reported a significant reduction of RVGE hospitalizations $[78,118,121,124,125,127,128,131$, $133,134,135,137], 10$ studies a reduction in the proportion of laboratory tests positive for RV [78, 122, 123, 126, 127, 129, 


\begin{tabular}{|c|c|c|c|c|c|c|c|c|c|c|}
\hline \multirow{2}{*}{$\begin{array}{l}\text { Study or Subgroup } \\
1.1 .1 \text { Crude OR, at least }\end{array}$} & $\begin{array}{l}\text { Cases } \\
\text { Events }\end{array}$ & \multirow[t]{2}{*}{ Total } & \multicolumn{2}{|c|}{$\begin{array}{l}\text { Controls } \\
\text { Events Total }\end{array}$} & \multirow[t]{2}{*}{ Weight } & \multicolumn{2}{|c|}{$\begin{array}{l}\text { Odds Ratio } \\
\text { M-H, Random, } 95 \% \mathrm{Cl}\end{array}$} & \multicolumn{2}{|c|}{$\begin{array}{l}\text { Odds Ratio } \\
\text { M-H, Random, } 95 \% \mathrm{Cl}\end{array}$} & \\
\hline & 2 doses & & & & & & & & & \\
\hline Boom_2010_RQ & 14 & 98 & 213 & 378 & $22.8 \%$ & $0.13[0.07,0.24]$ & & $-\square$ & & \\
\hline Castilla_2011_RX_RQ & 9 & 258 & 80 & 470 & $16.5 \%$ & $0.18[0.09,0.36]$ & & 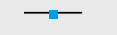 & & \\
\hline Cortese_2010_RQ & 22 & 265 & 815 & 2346 & $41.7 \%$ & $0.17[0.11,0.27]$ & & $\rightarrow$ & & \\
\hline Desai_2010_RQ-RX & 5 & 42 & 21 & 73 & $7.3 \%$ & $0.33[0.12,0.97]$ & & & & \\
\hline Guh_2011_RQ & 0 & 13 & 16 & 65 & $1.0 \%$ & $0.11[0.01,1.97]$ & 4 & & & \\
\hline Muhsen_2010_RX_RQ & 1 & 110 & 18 & 198 & $2.0 \%$ & $0.09[0.01,0.70]$ & & & & \\
\hline Staat_2011_RQ & 5 & 64 & 57 & 162 & $8.8 \%$ & $0.16[0.06,0.41]$ & & & & \\
\hline Subtotal $(95 \% \mathrm{Cl})$ & & 850 & & 3692 & $100.0 \%$ & $0.16[0.12,0.22]$ & & & & \\
\hline \multicolumn{9}{|c|}{$\begin{array}{l}\text { Total events } \\
\text { Heterogeneity: } \text { Tau }^{2}=0.00 ; \mathrm{Chi}^{2}=2.80, \mathrm{df}=6(\mathrm{P}=0.83) ; \mathrm{I}^{2}=0 \% \\
\text { Test for overall effect: } \mathrm{Z}=12.32(\mathrm{P}<0.00001)\end{array}$} & & \\
\hline \multicolumn{9}{|c|}{ 1.1.2 Crude OR, one dose } & & \\
\hline Boom_2010_RQ & 5 & 72 & 59 & 197 & $33.9 \%$ & $0.17[0.07,0.46]$ & & $\longrightarrow-$ & & \\
\hline Cortese_2010_RQ & 10 & 163 & 20 & 137 & $39.3 \%$ & $0.38[0.17,0.85]$ & & - & & \\
\hline Muhsen_2010_RX_RQ & 1 & 110 & 12 & 192 & $13.2 \%$ & $0.14[0.02,1.07]$ & & & & \\
\hline Staat_2011_RQ & 1 & 60 & 41 & 146 & $13.6 \%$ & $0.04[0.01,0.32]$ & & & & \\
\hline Subtotal $(95 \% \mathrm{Cl})$ & & 405 & & 672 & $100.0 \%$ & $0.19[0.08,0.44]$ & & & & \\
\hline Total events & 17 & & 132 & & & & & & & \\
\hline \multicolumn{9}{|c|}{$\begin{array}{l}\text { Heterogeneity: } \text { Tau }^{2}=0.31 ; \mathrm{Chi}^{2}=5.29, \mathrm{df}=3(P=0.15) ; \mathrm{I}^{2}=43 \% \\
\text { Test for overall effect: } Z=3.86(P=0.0001)\end{array}$} & & \\
\hline \multicolumn{6}{|c|}{ Test for subgroup differences: $\mathrm{Chi}^{2}=0.10, \mathrm{df}=1(\mathrm{P}=0.75), \mathrm{I}^{2}=0 \%$} & & 0.01 & 0.1 & 10 & 100 \\
\hline
\end{tabular}

Fig. $4<$ Forest plot of pooled odds ratios for the occurrence of rotavirus gastroenteritis (RVGE)-associated hospitalization by full or partial rotavirus ( $R V$ ) vaccination, case-control studies (2010-2011). (Cases $=$ children with RVGE and controls as defined in the respective study, event $=$ children having received a $R V$ vaccination at least 14 days before RVGE or RVnegative acute gastroenteritis ( $A G E$ ) occurred)
$132,133,136,141]$, and one study a decline of RV notifications [129], respectively, depending on the level of vaccination coverage, duration of observation period, and age distribution of observed subjects (study details and results are shown in Appendix III, Tab. 3, Tab. 4 , Tab. 5, Tab. 6). With respect to AGE of all causes, seven studies described a decline in hospitalizations or ED visits [118, 121, $126,128,133,137]$ and one study reported a decline in episodes of all cause AGE in children younger than 5 years treated as outpatients [121].

The identified studies consistently attested a strong effect of RV vaccination on different patient-relevant outcomes including hospitalization, RV infection, and all cause AGE, shown by various in vestigators in various settings. The effect also depicted a dose-response relationship at population level, with the magnitude of decreased disease incidence corresponding to the level of vaccination coverage. Despite the limitations inherent to ecological studies, the strength of effect, consistency over different study settings and investigators, and the population-based dose-response contribute to the confidence in the effects of RV vaccines and confirm the high vaccine efficacy identified in RCTs.

Impact on nosocomial infections and herd protection. Since herd protection and nosocomial infections cannot easily be assessed in RCTs, data from impact studies were used instead. Herd protection was assessed by 18 [78, 118, 121, 123, $124,125,126,127,128,129,131,132,133$, $134,135,137,138]$ of the included 22 studies, the other four studies did not report on this aspect. Of these 18 studies, 11 demonstrated a significant decrease of RVGE in age groups not eligible for vaccination, and two studies concluded on a possible effect (Appendix III). The included studies primarily considered children and adolescents under the age of 18. Additionally, herd protection regarding all cause AGE was observed in six studies. By contrast, five studies did not evidence herd protection. Parallel to observed herd protection, some studies reported a relative but not absolute increase of RVGE or all cause AGE in older age-groups or a higher median age in children hospitalized due to RVGE. Since herd protection depends on the achieved vaccination coverage in infants and coverage rates differed between the different considered studies, study results were not pooled and a pooled effect was not estimated. In the above-mentioned 11 studies, the incidence reduction in age groups not eligible for vaccination varied between $17-76 \%$.

Four studies described an effect of RV vaccines on nosocomial RVGE $[125,127$, 131, 134]. All four studies had an ecologi- cal study design, comparing rates of nosocomial infections before and after the introduction of RV vaccines. Data for calculations were extracted from three of these reports. Meta-analysis estimated that introduction of $\mathrm{RV}$ vaccines reduced the incidence of nosocomial infections by 76\% (95\%CI 40-91\%) (• Fig. 6) (Appendix III, Tab. 3, Tab. 4, Tab. 5, Tab. 6). The three studies pooled for meta-analysis had comparable settings with RV vaccination coverage of $31-87 \%$ and observation periods of 3-5 years after vaccine introduction.

Impact on $R V$-related mortality. Data from Mexico demonstrated a decrease in diarrhoea-related mortality in children under 5 years of age, amounting to 35\% in the 3rd season after introduction of RV vaccination, and $56 \%$ in the 4 th season $[139,140]$. Since fatalities due to RV infections are rare in industrialized countries, studies assessing the impact of RV vaccines on RVGE- and AGE-mortality were only performed in developing countries. However, their results are convincing and confirm the beneficial effects of RV vaccines, even though they are not transferable to the German healthcare system setting, where almost no RV-related mortality occurs.

Impact on viral strain replacement. Because of the short time period since the introduction of RV vaccines, data on re- 
placement of RV genotypes are scarce. Only four studies [78, 124, 134, 135] assessed possible replacement phenomena, one of them indicating that RV G2 serotype was emerging since RV vaccination was introduced [78]. However, a longer observation period is necessary to clearly differentiate between natural fluctuations and replacement due to vaccination. Based on the available literature, the level of evidence related to this effect must be regarded as very low.

Conclusion. The identified impact studies confirm our confidence in the effects of $\mathrm{RV}$ vaccines in reducing all cause AGE, RV infections, and hospitalization, in addition to data from RCTs. Furthermore, based on data from these impact studies, we are confident that a reduction in RV disease incidence in age groups not eligible for vaccination and in hospitalized individuals is also likely to occur. At this point of time, it is unknown if viral strain replacements after routine $\mathrm{RV}$ vaccine in troduction is likely to occur, and the quality of evidence concerning this question is still very low.

\section{Studies on vaccine impact and effectiveness in Germany published after the systematic literature review was accomplished}

In 2012-after the accomplishment of the above described systematic reviews-two observational studies were published that were conducted in Germany. One studied the impact of RV vaccination at population level [142], the other vaccine ef fectiveness and risk factors for vaccine failure in one German federal state [143]. This was possible since, despite not being adopted into the national immunization schedule, RV vaccines were available on the market since 2006, entailing a moderate $(58 \%)$ vaccine uptake in the 5 eastern federal states (EFS) and low (22\%) uptake in the 11 western federal states (WFS) in 2010, respectively.

The impact of RV vaccination was assessed by comparing the incidence rates (IR) of RV-related hospitalizations before (2004-2006) and after (2008/09-2010/11) $\mathrm{RV}$ vaccines became available in Germany, utilizing data from the national man- datory disease reporting system [58]. Overall reduction in IR reduction in age groups under 24 months was 36 and $25 \%$ in EFS and WFS, respectively. When computing IR ratios (IRR) in the seasons after mid-2006 with negative binomial regression, the effect of vaccination was independent of the geographic region. Vaccination was associated with a significant reduction in RV-related hospitalizations in children aged 6-23 months. Most remarkably, vaccination of $50 \%$ of all infants achieved an estimated $42 \%$ decrease of hospitalization rate in children in the age group 6-11 months. No significant reduction was observed in children aged 24 months or more, possibly due to the low/moderate vaccination coverage and the fact that noteworthy vaccination coverage was only achieved in the last 2 years. This study also demonstrated a decrease of nosocomial RV cases, which was, however, significant only in those aged younger than 12 months: $36-38 \%$ reduction was shown in the age group 6-11 months in both WFS and EFS [142]. $\mathrm{RV}$ vaccine effectiveness was assessed in 2010/11 in the federal state of Mecklenburg-Western Pomerania by applying the screening method, and an integrated case-control study was conducted to assess risk factors for breakthrough infection [143]. Vaccine effectiveness for the prevention of $\mathrm{RV}$ infection requiring medical attention or hospitalization was estimated at $68 \%(95 \% \mathrm{CI} 61-71)$ and $80 \%$ (95\%CI 77-83), respectively [144]. Vaccine effectiveness for preventing hospitalization but not medical attention remained stable over 2 years. Vaccinated children required hospitalization less often than unvaccinated RV-infected children $(23 \%$ vs. $61 \%$; p $<0.001)$. Breastfeeding $(\mathrm{OR}=3.99$; 95\% CI 1.92-8.27) and attending daycare $(\mathrm{OR}=3.42$; 95\% CI $1.64-$ 7.12) were independently associated with breakthrough infections. Genotype G1P [8] was detected more frequently in RQ-vaccinated ( $44 \%$ vs. $11 \%$; $<<0.03$ ) and G2P[4] in RX-vaccinated children ( $42 \%$ vs. $6 \%$; $\mathrm{p}<0.02$ ) [143].

\subsection{Safety of RV vaccines}

\section{Intussusception}

Intussusception is the most common cause of bowel obstruction in infants and young children. It occurs if one segment of the bowel is invaginated into the next. If the resulting obstruction is not relieved, the vascular supply of the bowel segment is compromised, resulting in ischemia; which may even be fatal [145]. After licensure of the first oral RV vaccine (Rotashield ${ }^{\circledR}$ ) in the US in 1998, a 37-fold higher than expected risk of intussusceptions was observed within 3-7 days following the 1st RV vaccine dose, which led to a market withdrawal of the vaccine only 9 months after its introduction [146]. The vaccine-attributable risk for Rotashield ${ }^{\circledR}$ was calculated to be around 1 per 5000-10,000 vaccinated children [147].

For these reasons increased attention with regard to intussusception was paid to the new generation of $\mathrm{RV}$ vaccines as well, and reliable baseline incidence data of intussusception for children in their first year of life are essential for post marketing monitoring. In a capture recapture analysis, the annual incidence of intussusception in infants (i.e. age $<12$ months) in Germany was estimated at 61.7/100,000 (95\%CI 54.5-70.1) [148]. The incidence varied by month of age with a range between 19.2/100,000 cases in the first 3 months and 98.5/100,000 cases at 6-8 months of life.

In the available Cochrane review, 13 trials reporting the incidence of intussusceptions after vaccination with RX or $R Q$ were included. We identified two additional studies that were published after the Cochrane review $[102,105]$, and we added these data to the meta-analysis. In total, 30 cases of intussusception were reported among 87,765 vaccinated children, compared to 19 cases among 79,418 children in the placebo arm (after pooling data from both vaccines: RR 1.21, 95\%CI 0.68-2.14) (• Fig. 7).

One of the largest studies included in the meta-analysis was a multicenter RCT that evaluated the efficacy and safety of RX in 63,225 infants in 10 Latin American countries and in Finland (• Fig. 7, study acronym: Ruiz-Palacios-2006-RX) 


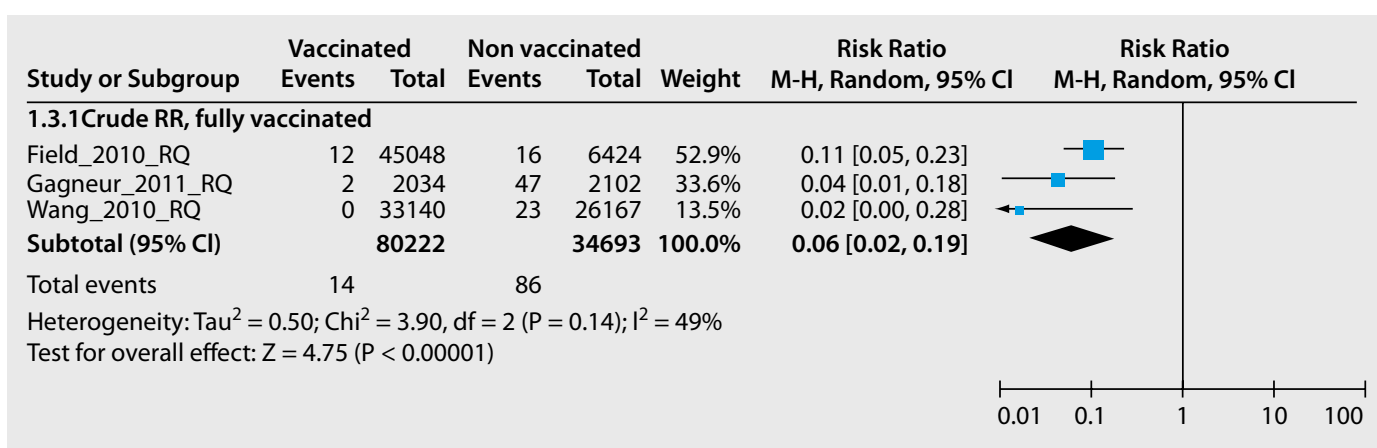

Fig. $5<$ Forest plot of pooled risk ratios for the occurrence of rotavirus gastroenteritis (RVGE)-associated hospitalization in fully rotavirus $(R V)$ vaccinated children, cohort studies (2010-2011). (Events = children with RVGE)
[100]. Healthy infants between 6 and 13 weeks of age received two oral doses 1-2 months apart. To assess the risk of intussusception, participants were monitored for 31 days after the administration of each dose. During this period, confirmed intussusception occurred in six of 31,673 vaccine recipients and seven of 31,522 placebo recipients (RR 0.85; 95\%CI $0.30-2.42$ ) after any dose. A clustering of cases after either dose was not observed.

For RQ, a multicentre trial conducted in 12 countries (Belgium, Costa Rica, Finland, Germany, Guatemala, Italy, Jamaica, Mexico, Puerto Rico, Sweden, Taiwan and USA) included 69,625 children; $82 \%$ were recruited in Finland and the USA (- Fig. 7, study acronym: Vesikari-2006RQ) [101]. Healthy infants between 6 and 12 weeks of age received three oral doses 4-10 weeks apart. All subjects were monitored for serious adverse events, including intussusception, for 42 days after each dose. During this period six confirmed intussusception cases occurred among 34,837 vaccine recipients and five among 34,788 placebo recipients (RR 1.6, 95\%CI 0.4-6.4) after any dose. A clustering of cases after any dose was not observed.

In summary, in the published RCTs no statistical significance between re ceipt of either RV vaccine and intussusception was identified [100, 101, 105]. No evidence of publication bias was detected regarding risk of intussusception (Appendix V, Fig. 5). However, even though the pre-licensure safety trials of both second-generation vaccines involved more than 130,000 subjects, they were underpowered to detect rare events occurring at rates below 1 in 50,000 vaccine recipients. For this reason, we decided to systematically review all available observational studies that assessed the risk of in- tussusception in the post-marketing period.

\section{Observational studies regarding risk of intussusception}

We identified 9 observational studies that met the inclusion criteria. Five studies evaluated RQ, two studies RX, and two further studies both RV vaccines. Details of the individual studies are presented in Appendix III (Tab. 7). Study results pointed to a slightly elevated relative risk for intussusception 1-7 days after the 1st dose of vaccination.

The five post-licensure studies exclusively examining the risk of intussusception following RQ vaccination were all conducted in the US between 2006 and 2010 [149, 150, 151, 152, 153]. Monitoring for intussusception was conducted in all but one study [152] by using data from the Vaccine Adverse Event Reporting System (VAERS), a national passive surveillance system, and the Vaccine Safety Datalink (VSD), a cohort of children enrolled in managed care. These data did not indicate any increased risk of intussusception after RQ, although the possibility of a marginal risk $(<1: 65,000)$ cannot be excluded [149, 150, 151, 153]. Until 2010, a total of 786,725 doses including 309,844 first doses have been administered, and no statistically significant risk augmentation was observed following either dose in the 1- to 7-day or the 1- to 30day risk window [153]. For the 1- to 7-day window after the 1st dose, one case was observed compared with 0.8 expected cases (standardized incidence ratio [SIR] 1.21 ; 95\%CI 0.03-6.75).

In Australia, two post-marketing studies on the risk of intussusception were conducted between 2007 and 2009 [154, 155]. The first study was conducted using two surveillance systems, the Paediatric Enhanced Disease Surveillance (PAEDS) hospital-based network and the Australian Paediatric Surveillance Unit (APSU) [154]. Through enhanced surveillance and an observed vs. expected analysis a four-fold increased risk in intussusception in infants within the 1- to 7-day period after the 1st dose of either vaccine was found, but no significant increase in overall intussusception rates up to the age of 9 months, compared with historical data (RR 3.5; 95\%CI 0.7-10.1). The second study, a large self-controlled case series, used data on all hospitalized cases coded as intussusception from four Australian territories [155]. A statistically significant four-fold increase in the occurrence of intussusception 1 to 7 days after the 1st dose of RQ or RX compared with other time periods after immunization was found (RR 4.1; 95\%CI 1.3-13.5) [155].

To assess the risk of intussusception after administration of RX, a case-series analysis and a case-control study were conducted in Mexico and Brazil between 2008 and 2010 [156]. In Mexico, an increased risk of intussusception within 1-7 days after the 1st dose was identified in both the case-series analysis (incidence ratio (IR) 5.3; 95\%CI 3.0-9.3) and the case-control method (OR 5.8; 95\% CI 2.6-13.0). In Brazil, where the 1st dose was co-administered with oral polio vaccine, risk was unaltered after the 1st dose, however increased after the 2nd dose in both the case-series analysis (IR 2.6; 95\%CI 1.3-5.2) and the case-control method (OR 1.9; 95\%CI 1.1-3.4).

In summary, post-marketing monitoring indicates the possibility of a slightly increased relative risk of intussusception shortly after the 1st dose of RV vaccines. The risk observed in the studies identi- 


\begin{tabular}{|c|c|c|c|c|c|c|c|c|}
\hline Study or Subgroup & log[Risk Ratio] & SE & Weight & $\begin{array}{c}\text { Risk Ratio } \\
\text { IV, Random, } 95 \% \mathrm{Cl}\end{array}$ & \multicolumn{4}{|c|}{$\begin{array}{c}\text { Risk Ratio } \\
\text { IV, Random, } 95 \% \mathrm{Cl}\end{array}$} \\
\hline Anderson_2011_RX_RQ & -0.9676 & 2.2381 & $4.2 \%$ & $0.38[0.00,30.54]$ & \multirow{4}{*}{\multicolumn{2}{|c|}{ - }} & & \\
\hline Buttery_2011_RX_RQ & -2.0402 & 0.3143 & $43.3 \%$ & $0.13[0.07,0.24]$ & & & & \\
\hline Paulke-Korinek_2010_RX_RQ & -0.9942 & 0.0694 & $52.5 \%$ & $0.37[0.32,0.42]$ & & & & \\
\hline Total $(95 \% \mathrm{Cl})$ & & & $100.0 \%$ & $0.24[0.09,0.60]$ & & & & \\
\hline \multicolumn{5}{|c|}{$\begin{array}{l}\text { Heterogeneity: } \text { Tau }^{2}=0.43 ; \mathrm{Chi}^{2}=10.56, \mathrm{df}=2(P=0.005) ; I^{2}=81 \% \\
\text { Test for overall effect: } Z=3.01(P=0.003)\end{array}$} & $\begin{array}{l}0.01 \\
0.01 \\
\text { ours exp }\end{array}$ & 0.1 & $\begin{array}{lr}1 & 10 \\
& \text { Favours }\end{array}$ & $\begin{array}{r}100 \\
\text { control }\end{array}$ \\
\hline
\end{tabular}

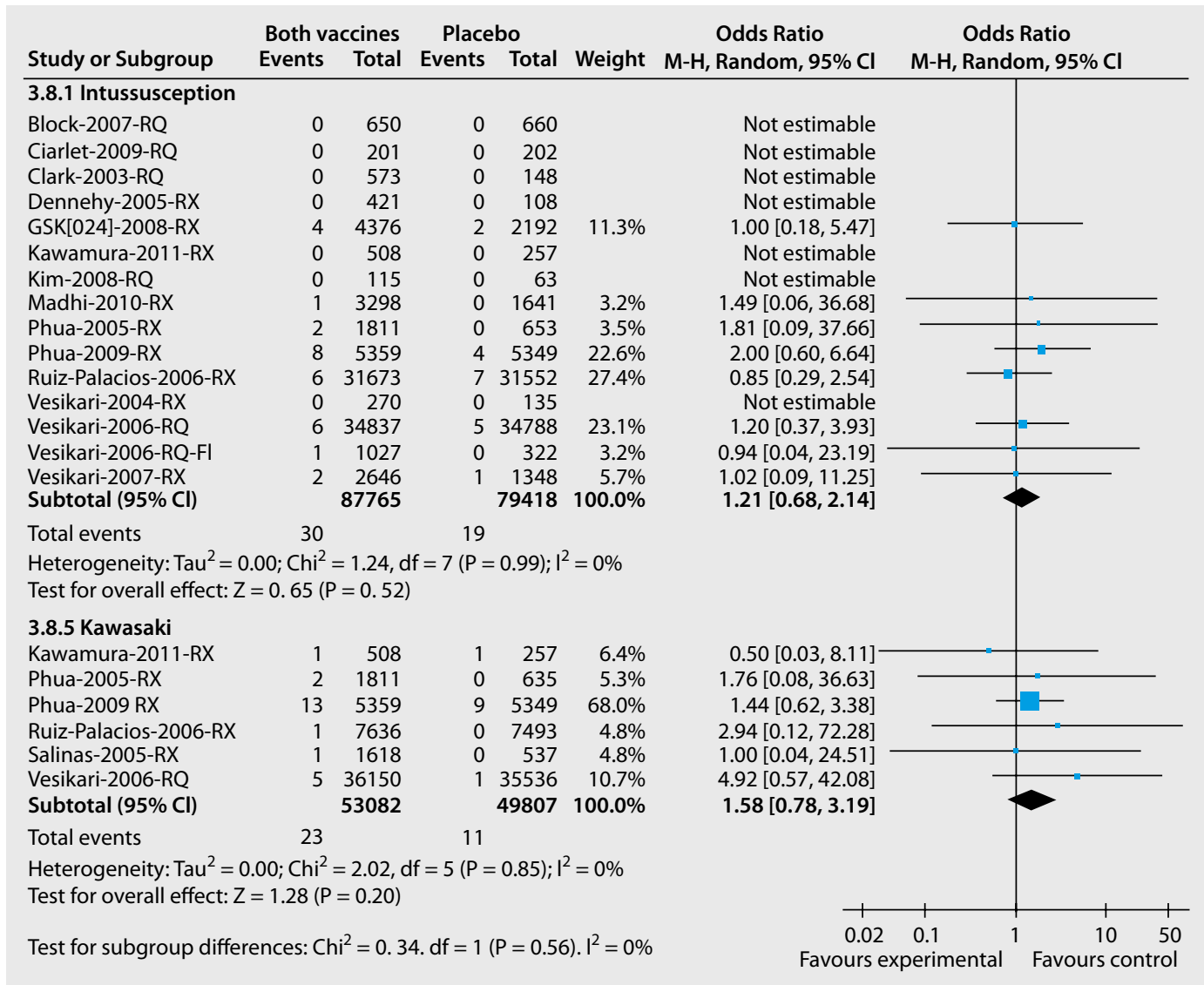

Fig. $6<$ Forest plot with pooled risk ratios for preventing nosocomial rotavirus gastroenteritis (RVGE), derived from ecological studies
Fig. $7<$ Forest plot with pooled data on the risk of intussusception and Kawasaki disease after RV vaccination from randomized controlled trials fied and included in this review is substantially lower than the risk in infants who received the Rotashield ${ }^{\circledR}$ vaccine, and corresponds to an absolute risk difference of approximately 1-2 additional cases of intussusception per 100,000 infants vaccinated.

Based on the experience with Rotashield $^{\circledR}$, WHO suggests that a higher risk of intussusception is also possible for RX and RQ if the 1st dose is administered to infants older than 12 weeks [157]. For Rotashield $^{\circledR}$, the association between vaccination and intussusception was dependent on the age at 1st dose, i.e. only children aged $>90$ days had an increased risk for this severe complication [81]. After RX and RQ were licensed in Europe, the Paul-Ehrlich-Institute (PEI), the national regulatory authority in Germany, conducted an observed versus expected analysis to investigate whether the risk for intussusception was elevated after vaccination with RX or RQ in Germany. Subgroup analyses revealed that infants aged 4-6 months were at increased risk to develop an intussusception 1-7 days after the 1st dose of either RV vaccine as compared to younger infants [158]. Therefore, the timely start of the vaccination series is highly recommended.

\section{Kawasaki disease}

Kawasaki disease is a rare childhood disorder of unknown aetiology that is characterized by high fever and inflamma- tion of the blood vessels, predominantly affecting coronary arteries [159]. Based on clinical and epidemiological features, an infectious etiology is strongly suspected. Kawasaki disease occurs worldwide in children of all races, but with regional variation of incidences. The highest incidences were observed in persons of Asian ethnicity $(138 / 100,000)$, while in Europe the incidence in children is estimated at $\leq 15 / 100,000$ person-years $[160,161]$.

In the above mentioned Cochrane review, two trials reported on the incidence of Kawasaki disease. We performed a systematic search in December 2011 covering the time period after conduct of the Cochrane review and identified additional four studies $[100,101,102,103]$. In the 


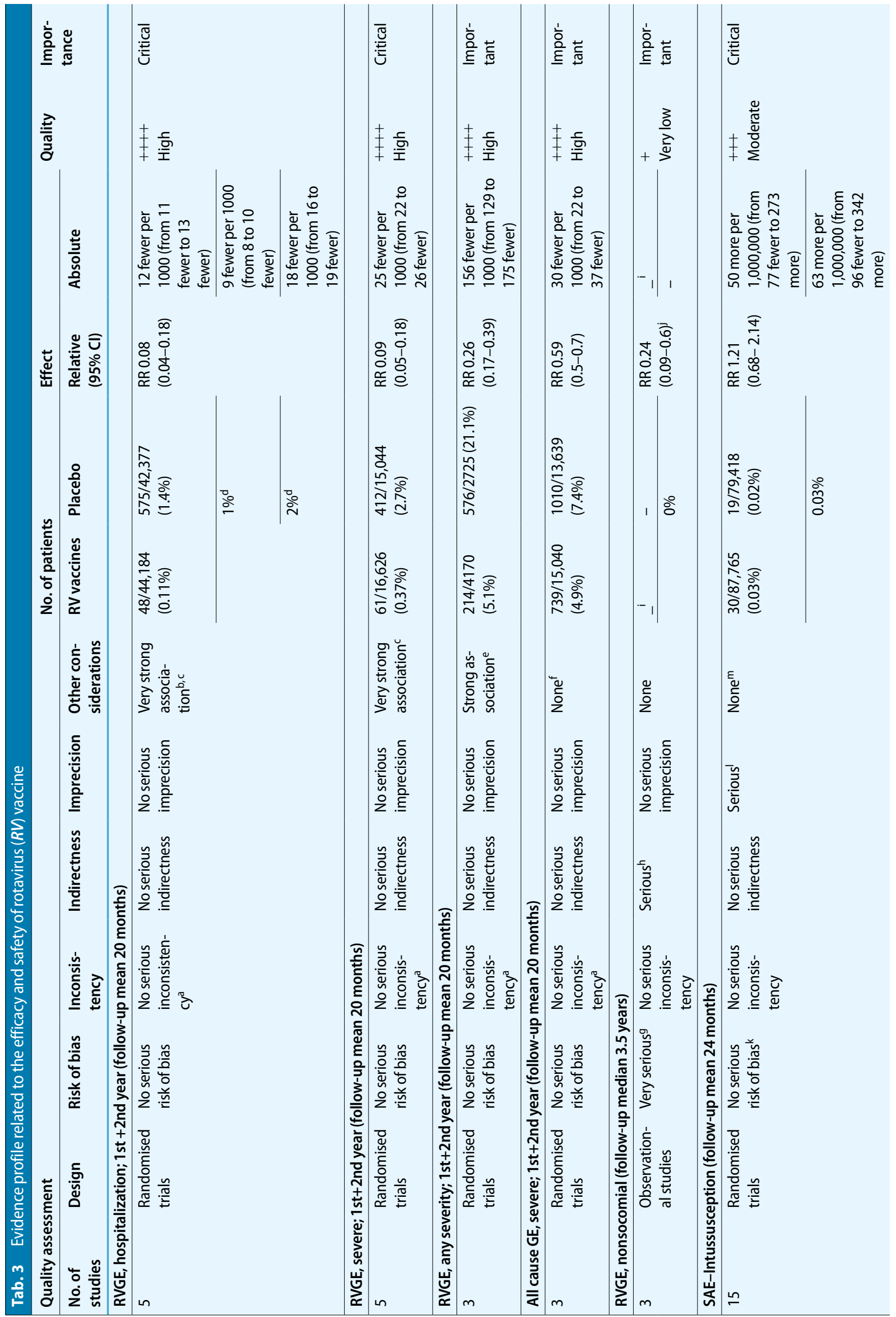




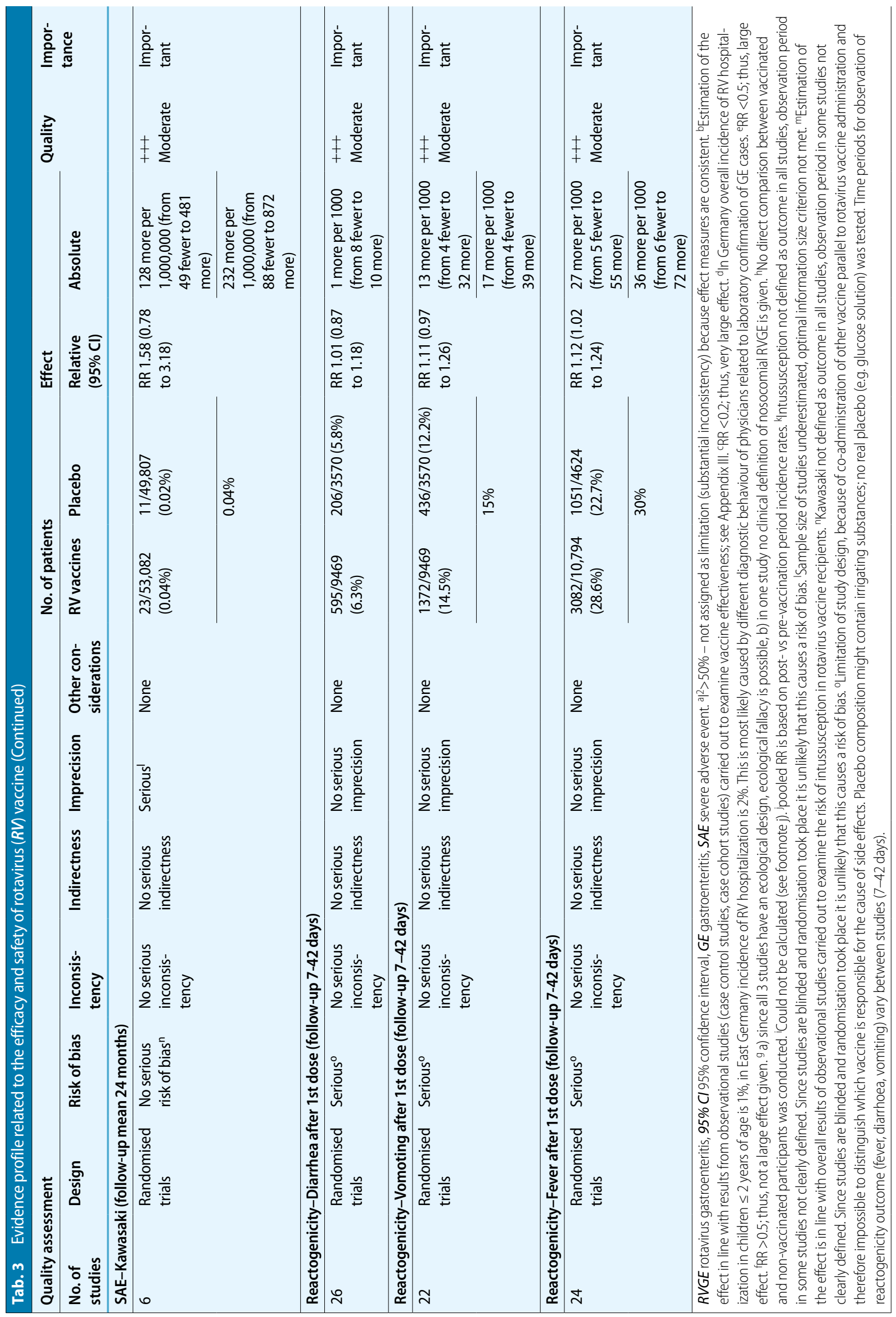


clinical trials providing data about Kawasaki disease, this was not listed as a predefined outcome, but cases were reported as serious adverse events. Therefore, no uniform definition for the case classification was applied. In the pooled analysis, 23 cases of Kawasaki disease were reported in a total of 53,082 vaccinated children, compared with 11 cases in 49,807 children in the placebo arm (• Fig. 7). In summary, no statistically significant increased risk for children receiving either RV vaccines was detected (RR 1.58, 95\%CI 0.783.18). There was no evidence of publication bias regarding risk of Kawasaki disease (Appendix V, Fig. 7).

In one RCT assessing efficacy and safety of RQ, 6 Kawasaki cases were identified; 5 among 36,150 vaccine recipients and 1 among 35,536 placebo recipients (crude RR 4.9; 95\%CI 0.6-239.1) [101]. All cases after administration of RQ occurred within 30 days after vaccination. Although the association was not statistically significant, the manufacturer added Kawasaki disease to the list of potential serious adverse events in the Summary of Product Characteristics in June 2007. Post-marketing monitoring for Kawasaki disease is currently ongoing, but so far no elevated risk of $\mathrm{Ka}$ wasaki disease after RQ vaccination was observed [162].

The serious adverse event database of PEI, the German regulatory authority, provides information on spontaneously reported cases of suspected adverse events following immunization in Germany. Since licensure of RV vaccines (time period: 2006-2010) four Kawasaki cases after vaccination with RQ and no case after vaccination with $\mathrm{RX}$ were reported in Germany, against the background that the two vaccines are used almost equally on the basis of survey results $[142,163,164]$. No clustering of cases with regard to age, gender and time of onset after vaccination was observed. According to PEI, as of today no association between $\mathrm{RV}$ vaccination and Kawasaki disease has been detected [165].

\section{Reactogenicity}

The incidences of fever, diarrhoea and vomiting following $\mathrm{RV}$ vaccination were evaluated at several time points after each dose and at the end of the followup period in most RCTs. Since the results for the different time points show identical point estimates, we decided to assess the pooled data for the events after the 1st dose. In the pooled analysis, no statistical significant differences were observed between the intervention arm (RQ or RX) and the placebo group for the occurrence of fever (RR 1.12; 95\%CI 1.02-1.24), vomiting (RR 1.11; 95\%CI 0.97-1.26), and diarrhoea (RR 1.01; 95\%CI 0.87-1.18) (Appendix IV). However, these figures must be interpreted with caution, since in most RCTs, the RV vaccine was co-administered with other childhood vaccines and the suspension which was used as a placebo might also cause adverse events itself. Therefore, it remains unclear whether fever, diarrhoea, or vomiting were attributable to the $\mathrm{RV}$ vaccine or not.

\subsection{Level of evidence related to $R V$ vaccine efficacy and safety}

Evidence of benefits and harms of RV vaccines was judged by the STIKO WG and is presented in the evidence profile (- Tab. 3). All data included in the evidence profile are from RCTs with the exception of nosocomial infections, which were evaluated in ecological (geographical association) studies. Quality assessment did not reveal any serious problems related to the evidence on the vaccine efficacy with regard to the considered outcomes. Therefore, the quality of evidence on vaccine efficacy in preventing RV-related hospitalization or severe RVGE was considered high. In addition, all RCTs consistently demonstrated a very strong protective effect of the vaccination. This effect was further confirmed by observational studies, which demonstrated strong effects of RV vaccination in populations with RV vaccination programs, and a stronger impact was observed in areas with higher vaccination coverage indicating a dose-response gradient at population level [142]. Though these observational studies were not considered in the evidence profile, they corroborate our confidence in the estimates of protective effects of RV vaccination. Regarding the impact of vaccination on nosocomial infections, the evidence had to be judged as very low, due to high risk of bias and indirectness (ecological study designs).

The quality of evidence related to adverse events following $R V$ vaccination was judged as moderate. The sample size of RCTs was not sufficient to reliably assess very rare events such as intussusception. However, evidence derived from observational studies suggests a slightly increased relative risk for intussusception with a magnitude, which still lies within the $95 \% \mathrm{CI}$ of the pooled analysis of data from RCTs (RR 1.21, 95\%CI 0.68-2.14). The quality of evidence related to reactogenicity was judged as moderate, since other childhood vaccines were co-administered and no fully inert placebo was used in the RCTs.

According to the GRADE methodology, the overall quality of evidence across all critical outcomes was moderate.

\section{Economic evaluation of RV vaccination in Germany}

In 2010/11 an economic evaluation was performed by an independent consultancy in cooperation with the RKI to estimate the costs of RV diarrhoea and RV vaccination with RX or RQ, and the costeffectiveness of RV vaccination in Germany from the perspective of the German statutory health insurance (GKV) and the societal perspective. The following health outcomes were considered: numbers of RV cases and RV-associated hospitalizations avoided, and quality-adjusted life years (QALY) gained. A time horizon of 5 years was considered. Here, we summarize the methodology and main results of the evaluation. The full report is available in German on the website of the RKI (http://www.rki.de/ impfen).

In November 2010, a systematic literature search was carried out to identify studies relevant for the efficacy, costeffectiveness and cost-utility ratio of RV vaccination. Databases considered were Medline, CRD Database and Cochrane Library. The systematic search covered publications between 2004 and November 2010. Only studies published in English, Spanish, German or French were included. Publications were selected based on defined inclusion and exclusion crite- 
ria. The systematic literature search was continually updated by hand-search until December 2011.

A Markov model with three health states (healthy, death due to RV infection, death due to other causes) was developed [174]. In each of the monthly cycles, an $\mathrm{RV}$ infection can occur, which is then treated either in hospital, on an outpatient basis or at home without healthcare consultation. Three intervention arms were compared in the model calculations: (1) no vaccination, (2) vaccination with RX and (3) vaccination with RQ. Costs and health outcomes were discounted at $3 \%$ per year. Price catalogues such as the German doctor's fee scale ("Einheitlicher Bewertungsmaßstab"), diagnosis-related groups (DRGs), or the German medical information website "Rote Liste" (http:// www.rote-liste.de) were used for the cost calculations. From the healthcare payer perspective, the following costs were considered: The costs per vaccine dose assigned in the model were $€ 67.51$ and $€ 45.09$ for RX and RQ, respectively (list price for the German market as of October 2011). The cost of physician service charge per vaccine dose application was set at $€ 6.50$. The average cost applied for outpatient and inpatient treatment of a RV disease case was $€ 49$ and $€ 1583$, re spectively. To avoid an overestimation of costs due to work loss and caring for the sick child, a conservative approach was chosen by calculating these costs based on the labor costs of women only. The applied costs for paid leave (transfer costs from GKV health insurance) for moth ers caring for their sick child were $€ 44$ for home and outpatient care, and $€ 62$ for inpatient care in the base-case analysis. The costs for surgical intervention for treatment of a case with intussusception following RV vaccination ( $€ 7451$ ) were included in a sensitivity analysis.

When considering the societal perspective, indirect costs (costs associated with loss in productivity due to work absenteeism of caring mothers) were included: $€ 76$ for outpatient and home care and $€ 106$ for inpatient care per RV case. In addition, direct non-medical costs were included in these calculations with a lump sum of $€ 20$ for increased use of diapers and transport costs.
Age- and treatment sector (inpatient/ outpatient)-stratified reporting data on $\mathrm{RV}$ incidence in children younger than 5 years for the time period 2001-2008 was provided by the RKI [5]. Presuming that a high number of RV cases remain undetected in a laboratory-based passive surveillance, the consistently higher RVincidences from the five eastern federal states in Germany (in comparison to 11 western federal states) was assumed to be more accurate. Therefore, the average incidence in the 5 eastern federal states was applied to the 11 western federal states for the same year, which ranged between 8.5 and 61.4 per 1000 children in the age groups 4-5 and 1-2 years, respectively. Furthermore, the number of patients without healthcare consultation was estimated by using a fixed multiplication factor (generated based on published literature) that was applied to the total number of reported RV cases.

The efficacy of RV vaccines was determined separately for both vaccines from RCTs identified in the systematic literature search. Only trials performed either in Europe or North America were considered [101, 104, 105, 175, 176, 177, 178, $179,180,181]$. Pooled effects were calculated in a meta-analysis with respect to the prevention of RV cases and RV-associated hospitalizations. For the basecase analysis of the model, a vaccine uptake of $80 \%$ was assumed. Since no utility scores were available for the German setting, we considered published utility scores that were established in the United Kingdom [182, 183]. Utility scores considered in the model ranged from 0.891 for mild, 0.781 for moderate, to 0.425 for severe RV-disease in children under the age of 18 months. The values used for children between 18 months and 4 years of age were 0.844 for mild, 0.688 for moderate and 0.200 for severe RV-disease. Utilities were adjusted for disease duration of 3 days and according to a cycle length of 1 month. For the base-case analysis the GKV perspective was used, and the proportion of RV cases without healthcare consultation (home care) was assumed to be $78 \%$ [3]. The effects and all direct medical costs as well as sick pay for caregiving parents from the GKV perspective were included in the base- case analysis. Several structural sensitivity analyses and one-way sensitivity analyses were performed. Intussusception as a possible (severe) adverse event associated with RV vaccination was not considered in the base-case analysis, but in a sensitivity analysis [184]. For the structural sensitivity analysis, the following input parameters were varied: The assumed proportion of RV cases without healthcare consultation (from 78 to 41.1 to $0 \%$ of all notified RV cases [185]), the duration of protection (from waning to stable immunity 3-5 years post vaccination), the efficacy of the RV vaccine (according to the $95 \% \mathrm{CI}$ of the pooled estimates), the number of RV cases in outpatient care (assuming no or $50 \%$ underdetection of RV cases in this sector), as well as inclusion of effects and costs from the societal perspective. An additional analysis considered the development of herd protection. One-way sensitivity analyses were carried out for vaccine dose price (0.5- to 1.5 -fold), vaccine administration costs ( 3 to $22 €$ ), costs for hospital and outpatient treatment, discount rate (0-10\%), vaccine uptake (60-90\%), and utility scores (children under the age of 18 months mild: $0.783-0.998$, moderate: 0.678-0.884, severe: $0.330-0.520$; children between 18 months and 4 years of age mild: $0.742-0.946$, moderate: $0.553-$ 0.824 , severe: $0.049-0.352$ ).

In the base-case, the incremental costeffectiveness ratio (ICER) for RX was $€ 184$ per RV-case prevented, $€ 2457$ per RV-associated hospitalization avoided, and $€ 116,969$ per QALY gained. For RQ, the results were $€ 234$ per RV-case prevented, $€ 2622$ per hospitalization avoided, and $€ 142,720$ per QALY gained. According to the sensitivity analyses of various parameters, the ICER of vaccination compared to no vaccination was most sensitive to variations in the vaccine dose price.

When applying the results from the base-case scenario to the 2012 German birth cohort and assuming a vaccine uptake of $80 \%$, the costs for vaccination would be 78-82 million Euro, resulting in an estimated 206,000-242,000 prevented RV-cases, 27,000-35,000 prevented outpatient-treated RV-cases, and 18,000 prevented RV-associated hospitalizations 
over 5 years. Therefore, healthcare costsavings would partially compensate the costs for vaccination. However, over a time period of 5 years, incremental costs amount to 44.5-48.2 million Euro.

Internal validity of the model was high as underlined by the comparison of the numbers of RV-infections calculated in the model and the observed absolute number of RV infections identified in the mandatory disease reporting system. The results of our analysis with regard to costs per RV-case prevented and hospitalization avoided were similar to those of other published cost-effectiveness studies identified in our systematic literature review. The costs per QALY gained were found to be different across studies, which may be attributable to different methodological approaches and/or the diversity of health system characteristics.

In conclusion, our analysis concerning the German healthcare system demonstrated that routine RV-vaccination could prevent a substantial number of RV cases and hospitalizations to higher costs. However, with vaccine prices reduced by approximately 62 to $66 \%$, $R V$ vaccination could even become a cost-saving preventive measure. Since there is no cost-effectiveness threshold in Germany, and since the utility scores were not derived from the German setting, the generated QALY results have to be interpreted with caution. In this analysis, each $R V$ vaccine was compared to a scenario of no vaccination. A comparison between the two vaccines was not part of this assessment, as appropriate data are not available from clinical trials.

\section{Immunization strategy and implementation of the recommendation}

\subsection{Immunization strategy and rationale for the recommendation}

The goal of this recommendation is to prevent RV infections requiring hospitalizations especially among infants and young children in Germany through routine $\mathrm{RV}$ vaccination of all infants.

RV causes a substantial disease burden in Germany. Although fatal cases are very rare, the annual incidence of severe gastroenteritis and RV-associated hospitalizations among children under 5 years of age is high. Each year, approximately 55,000 medically-attended RVGE cases are reported. In more than two thirds of cases, children under 5 years of age are affected and approximately half of them are treated in hospital. Since these are only passively reported RV cases with laboratory confirmation, a significant underestimation of the true disease burden based on these data can be assumed. As the virus is extremely resistant in the environment, and the minimal infective dose for transmission is low, hygiene improvements have very little effect on virus transmission and spread of RV disease. At the same time, two RV vaccines are available on the market, and several RCTs provided high quality evidence on their strong efficacy in preventing RV disease and RV-related hospitalization. The numbers needed to vaccinate calculated on the basis of the VE retrieved from RCTs are low: 80 infants must be vaccinated to prevent one RV-related hospitalization, 42 to prevent one severe RVGE and six to prevent one RVGE of any severity. Observational studies also provided evidence that children not eligible for RV immunization may benefit from indirect vaccination effects (herd protection), and that the number of nosocomial infections may decline.

Considering potential downsides of vaccination, the assessment of the quality of evidence related to the safety of $\mathrm{RV}$ vaccines revealed a moderate level of quality. Considering both RCTs and observational studies, a slightly increased relative risk of intussusception shortly after the 1st dose is possible, corresponding to 1-2 additional cases per 100,000 infants vaccinated. Another downside of routine vaccination is that-based on current vaccine dose prices-healthcare cost-savings would only partially compensate the costs for vaccination. Therefore, this intervention incurs considerable incremental costs.

After thoroughly weighting the benefits and downsides of this intervention, the STIKO recommends routine RV vaccination of children under the age of 6 months in Germany. There is no pref- erence for either of the two available RV vaccines. Although the absolute risk for intussusception following RV vaccination is very small, further monitoring will be necessary, and parents as well as physicians should be aware of this potential adverse event and the associated symptoms in order to take necessary action at an early stage. Timely vaccination with completion of the vaccination series before 24 or 32 weeks of age, depending on the product, should be reinforced. With the introduction of routine $R V$ vaccination, replacement and reassortment of RV strains might occur, but the vaccines have not yet been on the market for sufficiently long time to estimate the risk for these events. However, molecular surveillance systems are in place to monitor and detect possible changes. Furthermore, a mandatory countrywide disease reporting system has been in place for more than 10 years. This system will be utilized to estimate the impact of RV vaccination on RV disease incidence in various age groups and to evaluate to which extent the primary goal of reducing RVrelated hospitalizations will be achieved.

\subsection{Implementation of the recommendation}

\section{Dosage and schedule}

The vaccination series of RQ consists of three oral doses. The 1st dose should be administered as early as possible from the age of 6 weeks and up to the age of 12 weeks. The vaccination series of three doses should preferably be completed before the age of 20-22 weeks, and latest by the age of 32 weeks. Doses should be given at least 4 weeks apart [87]. The vaccination course of RX consists of two vaccine doses. The 1st dose should be administered as early as possible after the age of 6 weeks. The vaccination series should preferably be completed before 16 weeks of age, and latest by the age of 24 weeks. Doses should be given at least 4 weeks apart [84].

\section{Concomitant administration with other childhood vaccines}

Oral RV vaccination can be easily adopted into the national immunization schedule as it can be administered con- 
comitantly with other standard vaccines of early childhood. Concomitant application of RV vaccines with Diphtheria-tetanus-acellular pertussis vaccine (DTaP), Haemophilus influenzae type $\mathrm{b}$ vaccine (Hib), inactivated poliovirus vaccine (IPV), hepatitis B vaccine (HBV) and pneumococcal conjugate vaccine (PCV) has been evaluated. These studies demonstrated that the immune responses and the safety profiles of all administered vaccines, irrespective of monovalent or combination vaccine use, were unaffected [ 84 , 87].

\section{Premature infants}

Data suggest that preterm infants are at increased risk for hospitalization from RVGE during the first 1-2 years of life [166]. RQ or RX should be given to prematurely born infants provided that the period of gestation was at least 25 (RQ) or 27 (RX) weeks. Like maturely born infants, preterm infants should receive the 1st vaccine dose 6 weeks after birth, or the earliest possible time thereafter $[167,168]$.

\section{Previous RV infection}

Infants having suffered a RVGE before receiving the full course of $\mathrm{RV}$ vaccination should nevertheless begin or complete the vaccination course, because the initial infection provides only partial immunity for the prevention of subsequent RV disease [169].

\section{Contraindications}

$\mathrm{RV}$ vaccines are contraindicated in children with severe combined immunodeficiency (SCID). SCID includes several rare, life-threatening genetic disorders resulting in deficient $\mathrm{T}$ - and/or Blymphocyte function. The estimated annual incidence of SCID is one case per 50,000-100,000 live births [170]. Infants with SCID commonly experience chronic diarrhoea, failure to thrive and early onset of severe infectious diseases. SCID is usually diagnosed after an infant has acquired a severe, potentially life-threatening infection caused by one or more pathogens. Between 2006 and 2010, eight infants were diagnosed in the US with SCID between the age of 3 and 9 months who had received $1-3$ doses of $R V$ vaccine before the diagnosis was made $[171,172]$.
Infants with other known or suspected altered immunocompetence should be presented to a clinical immunologist before RV vaccine administration. Infants with a previous history of intussusception or with uncorrected congenital malformations of the gastrointestinal tract that would predispose for intussusception should not be vaccinated against RV. Children who have a history of anaphylactic reaction to any component of the vaccine or showed hypersensitivity after previous administration of $\mathrm{RV}$ vaccines should also not be vaccinated nor receive further doses [84, 87].

\section{Viral shedding and transmission of vaccine virus}

RX-prelicensure studies reported that shedding of RV can be detected in $50 \%$ (35-80\%) of RX vaccine recipients and is more common after the 1st dose than after the 2 nd dose (4\%). Excretion of RX peaked around the 7 th day post vaccination. Live vaccine strains were present in approximately $17 \%$ of cases with viral shedding. Transmission of excreted vaccine virus to seronegative contacts of vaccinees has been observed, however, without causing clinical symptoms [84, 97, 173]. Shedding of RQ occurred in $0-13 \%$ of vaccine recipients in clinical trials after the 1st dose, in $0-7 \%$ after the 2 nd dose and in $0-4 \%$ after the 3 rd dose. Transmission of RQ, although not as well studied as for RX, might be less likely because of a larger inoculum dose required for infection $[87,96,173]$. Nevertheless, RV vaccines should be administered with caution to infants with close contact to immunocompromised persons. These contacts should be advised to avoid contact with the stool of the vaccinated child, for at least 14 days, particularly after the 1 st dose.

\section{Evaluation of the vaccination recommendation}

When introducing RV vaccination into a national immunization program, adequate surveillance systems are crucial to monitor the vaccine's impact at population level and to detect rare adverse events related to the vaccine in a timely manner. In Germany, several systems exist to monitor the effects of RV vaccination.

\section{Monitoring of RV disease epidemiology}

With the implementation of the Protection against Infection Act in 2001, RV became a notifiable disease in Germany [58]. On a weekly basis, case-based information on laboratory-confirmed acute $\mathrm{RV}$ infections is collected countrywide by local health authorities, initiated by the notification of all positive RV test results in local laboratories. The information on each case includes age, sex, residency, onset of symptoms, hospitalization, fatal outcome, laboratory method used for diagnosis and RV vaccination status. Data are electronically forwarded from the local health authority via the state health department to the federal public health institute, the RKI [186]. As the disease reporting system has not been modified since its inauguration, the data are suitable to determine the impact of $R V$ vaccination on RVGE incidence and RV-related hospitalization in all age groups. They also allow the detection of possible effects in older age-groups not eligible for vaccination. In addition to the mandatory disease reporting system, the Federal Statistic Office of Germany routinely retrieves RV discharge diagnoses from hospitals, which can be used for external validation of the national surveillance data with regard to the goal of the recommendation: The reduction of hospitalizations due to RV (https://www. gbe-bund.de).

\section{Molecular surveillance of RV}

Molecular strain surveillance is established in Germany at the Consulting Laboratory for RV infections at RKI. Here, methods and algorithms for effective RV typing are well established to describe in detail the molecular epidemiology of circulating RV viruses, during each consecutive RV season, through genotyping of $\mathrm{RV}$-positive samples representative for all parts of Germany [12, 70]. The emergence and spread of common and novel RV strains is examined and can be used to detect possible vaccine-induced replacement or escape mutants, or genotypes other than those included in the 
vaccine as well as reassortants between viral vaccine components and naturally circulating wild-type strains. In addition, RV strains responsible for breakthrough infections can be genotyped. The German Consulting Laboratory is an associated partner of the EuroRotaNet, which was established in January 2007, and has conducted continuous RV strain surveillance in Europe ever since [12].

\section{Monitoring of adverse events}

In Germany, a spontaneous reporting system legally obliging manufacturers to report suspected adverse drug reactions (ADR) according to the German Drug Law and European Regulations has been established for many years [187]. A second legal tool is embedded in the German Protection against Infection Act. According to this law, physicians are requested to report any suspected adverse events following immunization (AEFI) to the national regulatory author ity PEI [188]. Based on these spontaneously reported data it is possible to perform observed vs. expected analyses to investigate whether specific events occur more frequently in recently vaccinated children than expected in children in the same age group (as background incidence) and to apply quantitative methods of disproportionality (e.g. proportionate rate ratio, PRR) [189]. With these types of tools, even very rare AEFI such as intussusception following RV vaccination can be monitored.

\section{$R V$ vaccination coverage}

In Germany, vaccination coverage is routinely assessed at school entry, covering all children aged 5-6 years who present their vaccination record (acquisition of data varied in 2009 between 87 and 95\% in the 16 federal states) [190]. There is no immunization register, which could provide information on the vaccination status of other age groups, for example the target population for RV vaccination. However, routine vaccination coverage data for children aged 12 or 24 months are essential to monitor RV vaccine uptake and acceptance within a short time span of vaccination activities. An alternative source of information could be a joint project of the RKI and the 17 associations of statutory health insurance physicians (ASHIPs) that provide anonymous physicians' fee-for-vaccination billing data to the RKI. Countrywide vaccination coverage among persons insured by a statutory health insurance (i.e. approximately $85 \%$ of the German population) can thus be determined in a cohort fashion. However, also with the ASHIP data there is a delay in providing and analyzing the data of up to 1 year.

In conclusion, a reliable disease and molecular surveillance system exists for $\mathrm{RV}$, able to provide robust case-based data on the RV epidemiology of the pre- and post-vaccination era, suitable to monitor the impact of RV vaccinations as well as potential replacement phenomena or reassortment with vaccine strains. There is also a passive AEFI surveillance system that captures spontaneously reported adverse events. Countrywide vaccination coverage will be available only with a considerable time delay.

\section{Corresponding address}

\section{Dr. J. Koch}

Immunization Unit, Robert Koch Institute

DGZ-Ring 1, 13086 Berlin

Germany

kochj@rki.de

Conflict of interest. EG received funding from GSK and SPMSD for studies on vaccines unrelated to rotavirus. HO worked as a consultant for GSK and Sanofi Pasteur MSD in the last 5 years. AMM participated in a study on the molecular epidemiology of rotavirus infections that had received financial support by EuroRotaNet until 2010. All other authors state that there are no conflicts of interest.

\section{References}

1. Parashar UD, Gibson CJ, Bresse JS, Glass RI (2006) Rotavirus and severe childhood diarrhea. Emerg Infect Dis 12:304-306

2. Tate JE, Burton AH, Boschi-Pinto C et al (2012) 2008 estimate of worldwide rotavirus-associated mortality in children younger than 5 years before the introduction of universal rotavirus vaccination programmes: a systematic review and meta-analysis. Lancet Infect Dis 12:136141

3. Soriano-Gabarro M, Mrukowicz J, Vesikari T, Verstraeten T (2006) Burden of rotavirus disease in European Union countries. Pediatr Infect Dis J 25:S7-S11
4. Bouzon-Alejandro M, Redondo-Collazo L, Sanchez-Lastres JM et al (2011) Prospective evaluation of indirect costs due to acute rotavirus gastroenteritis in Spain: the ROTACOST study. BMC Pediatr 11:81

5. Koch J, Wiese-Posselt M (2011) Epidemiology of rotavirus infections in children less than 5 years of age: Germany, 2001-2008. Pediatr Infect Dis J 30:112-117

6. World Health Organization (2009) Meeting of the immunization Strategic Advisory Group of Experts, April 2009-conclusions and recommendations. Wkly Epidemiol Rec 84:220-236

7. Estes MK, Cohen J (1989) Rotavirus gene structure and function. Microbiol Rev 53:410-449

8. Iturriza Gomara M, Wong C, Blome S et al (2002) Molecular characterization of VP6 genes of human rotavirus isolates: correlation of genogroups with subgroups and evidence of independent segregation. J Virol 76:6596-6601

9. Santos N, Hoshino Y (2005) Global distribution of rotavirus serotypes/genotypes and its implication for the development and implementation of an effective rotavirus vaccine. Rev Med Virol 15:29-56

10. Matthijnssens J, Ciarlet M, Rahman M et al (2008) Recommendations for the classification of group A rotaviruses using all 11 genomic RNA segments. Arch Virol 153:1621-1629

11. Abe M, Ito N, Masatani T et al (2011) Whole genome characterization of new bovine rotavirus G21P[29] and G24P[33] strains provides evidence for interspecies transmission. J Gen Virol 92:952-960

12. Iturriza-Gomara M, Dallman T, Banyai $K$ et al (2011) Rotavirus genotypes co-circulating in Europe between 2006 and 2009 as determined by EuroRotaNet, a pan-European collaborative strain surveillance network. Epidemiol Infect 139:895-909

13. Gleizes $O$, Desselberger U, Tatochenko V et al (2006) Nosocomial rotavirus infection in European countries: a review of the epidemiology, severity and economic burden of hospitalacquired rotavirus disease. Pediatr Infect Dis J 25:12-21

14. Stockman LJ, Staat MA, Holloway M et al (2008) Optimum diagnostic assay and clinical specimen for routine rotavirus surveillance. J Clin Microbiol 46:1842-1843

15. Doern GV, Herrmann JE, Henderson P et al (1986) Detection of rotavirus with a new polyclonal antibody enzyme immunoassay (Rotazyme II) and a commercial latex agglutination test (Rotalex): comparison with a monoclonal antibody enzyme immunoassay. J Clin Microbiol 23:226-229

16. Wilde J, Van R, Pickering L et al (1992) Detection of rotaviruses in the day care environment by reverse transcriptase polymerase chain reaction $\mathrm{J}$ Infect Dis 166:507-511

17. Ansari SA, Sattar SA, Springthorpe VS et al (1988) Rotavirus survival on human hands and transfer of infectious virus to animate and nonporous inanimate surfaces. J Clin Microbiol 26:1513-1518

18. Ansari SA, Springthorpe VS, Sattar SA (1991) Survival and vehicular spread of human rotaviruses: possible relation to seasonality of outbreaks. Rev Infect Dis 13:448-461 
19. Ward RL, Bernstein DI, Young EC et al (1986) Human rotavirus studies in volunteers: determination of infectious dose and serological response to infection. J Infect Dis 154:871-880

20. Ward RL, Knowlton DR, Pierce MJ (1984) Efficiency of human rotavirus propagation in cell culture. J Clin Microbiol 19:748-753

21. Mandell GL, Bennett JE, Dolin R (2010) Mandell, Douglas, and Bennett's principles and practice of infectious diseases. Churchill Livingstone/ Elsevier, Philadelphia

22. Chandran A, Heinzen RR, Santosham M, Siberry GK (2006) Nosocomial rotavirus infections: a systematic review. J Pediatr 149:441-447

23. Tran A, Talmud D, Lejeune B et al (2010) Prevalence of rotavirus, adenovirus, norovirus, and astrovirus infections and coinfections among hospitalized children in northern France. J Clin Microbiol 48:1943-1946

24. Rodriguez WJ, Kim HW, Brandt CD et al (1979) Common exposure outbreak of gastroenteritis due to type 2 rotavirus with high secondary attack rate within families. J Infect Dis 140:353357

25. Hu L, Crawford SE, Hyser JM et al (2012) Rotavirus non-structural proteins: structure and function. Curr Opin Virol 2:380-388

26. Ward LA, Rosen BI, Yuan L, Saif LJ (1996) Pathogenesis of an attenuated and a virulent strain of group $A$ human rotavirus in neonatal gnotobiotic pigs. J Gen Virol 77(Pt 7):1431-1441

27. Ball JM, Tian P, Zeng CQ et al (1996) Age-dependent diarrhea induced by a rotaviral nonstructural glycoprotein. Science 272:101-104

28. Davidson GP, Bishop RF, Townley RR, Holmes IH (1975) Importance of a new virus in acute sporadic enteritis in children. Lancet 1:242-246

29. Kapikian AZ, Wyatt RG, Levine MM et al (1983) Oral administration of human rotavirus to volunteers: induction of illness and correlates of resistance. J Infect Dis 147:95-106

30. Johansen K, Hedlund KO, Zweygberg-Wirgart B, Bennet R (2008) Complications attributable to rotavirus-induced diarrhoea in a Swedish paediatric population: report from an 11-year surveillance. Scand J Infect Dis 40:958-964

31. Carlson JA, Middleton PJ, Szymanski MT et al (1978) Fatal rotavirus gastroenteritis: an analysis of 21 cases. Am J Dis Child 132:477-479

32. Dickey M, Jamison L, Michaud L et al (2009) Rotavirus meningoencephalitis in a previously healthy child and a review of the literature. Pediatr Infect Dis J 28:318-321

33. Rodriguez WJ, Kim HW, Arrobio JO et al (1977) Clinical features of acute gastroenteritis associated with human reovirus-like agent in infants and young children. J Pediatr 91:188-193

34. Ruuska T, Vesikari T (1990) Rotavirus disease in Finnish children: use of numerical scores for clinical severity of diarrhoeal episodes. Scand J Infect Dis 22:259-267

35. Rivest $P$, Proulx M, Lonergan $G$ et al (2004) Hospitalisations for gastroenteritis: the role of rotavirus. Vaccine 22:2013-2017

36. Gurwith M, Wenman W, Hinde D et al (1981) A prospective study of rotavirus infection in infants and young children. J Infect Dis 144:218224

37. Gimenez-Sanchez F, Delgado-Rubio A, Martinon-Torres F et al (2010) Multicenter prospective study analysing the role of rotavirus on acute gastroenteritis in Spain. Acta Paediatr 99:738-742
38. Albano F, Bruzzese E, Bella A et al (2007) Rotavirus and not age determines gastroenteritis severity in children: a hospital-based study. Eur J Pediatr 166:241-247

39. Rodriguez WJ, Kim HW, Brandt CD et al (1987) Longitudinal study of rotavirus infection and gastroenteritis in families served by a pediatric medical practice: clinical and epidemiologic observations. Pediatr Infect Dis J 6:170-176

40. Desselberger U (1999) Rotavirus infections: guidelines for treatment and prevention. Drugs 58:447-452

41. Gilger MA, Matson DO, Conner ME et al (1992) Extraintestinal rotavirus infections in children with immunodeficiency. J Pediatr 120:912-917

42. Oishi I, Kimura T, Murakami T et al (1991) Serial observations of chronic rotavirus infection in an immunodeficient child. Microbiol Immunol 35:953-961

43. Liakopoulou E, Mutton K, Carrington D et al (2005) Rotavirus as a significant cause of prolonged diarrhoeal illness and morbidity following allogeneic bone marrow transplantation. Bone Marrow Transplant 36:691-694

44. Stelzmueller I, Wiesmayr S, Swenson BR et al (2007) Rotavirus enteritis in solid organ transplant recipients: an underestimated problem? Transpl Infect Dis 9:281-285

45. Naficy AB, Abu-Elyazeed R, Holmes JL et al (1999) Epidemiology of rotavirus diarrhea in Egyptian children and implications for disease control. Am J Epidemiol 150:770-777

46. Newburg DS, Peterson JA, Ruiz-Palacios GM et al (1998) Role of human-milk lactadherin in protection against symptomatic rotavirus infection. Lancet 351:1160-1164

47. Clemens J, Rao M, Ahmed F et al (1993) Breastfeeding and the risk of life-threatening rotavirus diarrhea: prevention or postponement? Pediatr 92:680-685

48. Plenge-Bonig A, Soto-Ramirez N, Karmaus W et al (2010) Breastfeeding protects against acute gastroenteritis due to rotavirus in infants. Eur J Pediatr 169:1471-1476

49. Dennehy PHM, Cortese MMM, Begue REM et al (2006) A Case-Control Study to determine risk factors for hospitalization for rotavirus gastroenteritis in U.S. children. Pediatr Infect Dis J 25:1123-1131

50. Parashar UD, Burton A, Lanata C et al (2009) Global mortality associated with rotavirus disease among children in 2004. J Infect Dis 200(Suppl 1):S9-S15

51. Parashar UD, Holman RC, Clarke MJ et al (1998) Hospitalizations associated with rotavirus diarrhea in the United States, 1993 through 1995: surveillance based on the new ICD-9-CM rotavirus-specific diagnostic code. J Infect Dis 177:1317

52. Widdowson MA, Meltzer MI, Zhang X et al (2007) Cost-effectiveness and potential impact of rotavirus vaccination in the United States. Pediatr 119:684-697

53. Bilcke J, Van Damme P, Van Ranst M et al (2009) Estimating the incidence of symptomatic rotavirus infections: a systematic review and metaanalysis. PloS ONE 4:e6060

54. Payne DC, Staat MA, Edwards KM et al (2008) Active, population-based surveillance for severe rotavirus gastroenteritis in children in the United States. Pediatr 122:1235-1243
55. Ray PG, Kelkar SD, Walimbe AM et al (2007) Rotavirus immunoglobulin levels among Indian mothers of two socio-economic groups and occurrence of rotavirus infections among their infants up to 6 months. J Med Virol 79:341-349

56. Duffy LC, Byers TE, Riepenhoff-Talty M et al (1986) The effects of infant feeding on rotavirus-induced gastroenteritis: a prospective study. Am J Public Health 76:259-263

57. Velazquez FR, Matson DO, Calva JJ et al (1996) Rotavirus infections in infants as protection against subsequent infections. N Engl J Med 335:1022-1028

58. Krause G, Altmann D, Faensen D et al (2007) SurvNet electronic surveillance system for infectious disease outbreaks, Germany. Emerg Infect Dis 13:1548-1555

59. Hsu VP, Staat MA, Roberts N et al (2005) Use of active surveillance to validate international classification of diseases code estimates of rotavirus hospitalizations in children. Pediatr 115:78-82

60. Shai S, Perez-Becker R, Konig CH von et al (2012) Rotavirus disease in Germany-a prospective survey of very severe cases. Pediatr Infect Dis J 32:e62-e67

61. Garbarg-Chenon A, Bricout F, Nicolas JC (1984) Study of genetic reassortment between two human rotaviruses. Virology 139:358-365

62. Unicomb LE, Podder G, Gentsch JR et al (1999) Evidence of high-frequency genomic reassortment of group A rotavirus strains in Bangladesh: emergence of type G9 in 1995. J Clin Microbiol 37:1885-1891

63. Gentsch JR, Laird AR, Bielfelt B et al (2005) Serotype diversity and reassortment between human and animal rotavirus strains: implications for rotavirus vaccine programs. J Infect Dis 192(Suppl 1):146-159

64. Saif LJ, Jiang B (1994) Nongroup A rotaviruses of humans and animals. Curr Top Microbiol Immunol 185:339-371

65. Martella V, Banyai K, Matthijnssens J et al (2010) Zoonotic aspects of rotaviruses. Vet Microbiol 140:246-255

66. Midgley SE, Hjulsager CK, Larsen LE et al (2012) Suspected zoonotic transmission of rotavirus group $A$ in Danish adults. Epidemiol Infect 140:1013-1017

67. Matthijnssens J, Heylen E, Zeller M et al (2010) Phylodynamic analyses of rotavirus genotypes G9 and G12 underscore their potential for swift global spread. Mol Biol Evol 27:2431-2436

68. Matthijnssens J, Bilcke J, Ciarlet M et al (2009) Rotavirus disease and vaccination: impact on genotype diversity. Future Microbiol 4:13031316

69. Usonis V, Ivaskeviciene I, Desselberger U, Rodrigo C (2012) The unpredictable diversity of cocirculating rotavirus types in Europe and the possible impact of universal mass vaccination programmes on rotavirus genotype incidence. Vaccine 30:4596-4605

70. Mas Marques A, Diedrich S, Huth C, Schreier E (2007) Group A rotavirus genotypes in Germany during 2005/2006. Arch Virol 152:1743-1749

71. Iturriza-Gomara M, Dallman T, Banyai K et al (2009) Rotavirus surveillance in Europe, 20052008: web-enabled reporting and real-time analysis of genotyping and epidemiological data. J Infect Dis 200(Suppl 1):S215-S221 
72. Desselberger U, Huppertz HI (2011) Immune responses to rotavirus infection and vaccination and associated correlates of protection. J Infect Dis 203:188-195

73. Zeller M, Patton JT, Heylen E et al (2012) Genetic analyses reveal differences in the VP7 and VP4 antigenic epitopes between human rotaviruses circulating in Belgium and rotaviruses in Rotarix and RotaTeq. J Clin Microbiol 50:966-976

74. Clark HF, Lawley D, DiStefano D et al (2011) Distribution of rotavirus genotypes causing nosocomial and community-acquired acute gastroenteritis at the Children's Hospital of Philadelphia in the new rotavirus vaccine era. Hum Vaccin 7:1118-1123

75. Hull JJ, Teel EN, Kerin TK et al (2011) United States rotavirus strain surveillance from 2005 to 2008: genotype prevalence before and after vaccine introduction. Pediatr Infect Dis J 30:4247

76. Kirkwood CD, Boniface K, Bishop RF et al (2009) Australian rotavirus surveillance program annual report, 2008/2009. Commun Dis Intell 33:382-388

77. Nakagomi T, Cuevas LE, Gurgel RG et al (2008) Apparent extinction of non- $\mathrm{G} 2$ rotavirus strains from circulation in Recife, Brazil, after the introduction of rotavirus vaccine. Arch Virol 153:591593

78. Zeller M, Rahman M, Heylen E et al (2010) Rotavirus incidence and genotype distribution before and after national rotavirus vaccine introduction in Belgium. Vaccine 28:7507-7513

79. Kapikian AZ, Hoshino Y, Chanock RM, PerezSchael I (1996) Efficacy of a quadrivalent rhesus rotavirus-based human rotavirus vaccine aimed at preventing severe rotavirus diarrhea in infants and young children. J Infect Dis 174(Suppl 1):65-72

80. Centers for Disease C, Prevention (1999) Withdrawal of rotavirus vaccine recommendation. MMWR Morb Mortal Wkly Rep 48:1007

81. Simonsen L, Viboud C, Elixhauser A et al (2005) More on RotaShield and intussusception: the role of age at the time of vaccination. J Infect Dis 192(Suppl 1):36-43

82. Bernstein DI, Smith VE, Sherwood JR et al (1998) Safety and immunogenicity of live, attenuated human rotavirus vaccine $89-12$. Vaccine 16:381-387

83. De Vos B, Vesikari T, Linhares AC et al (2004) A rotavirus vaccine for prophylaxis of infants against rotavirus gastroenteritis. Pediatr Infect Dis J 23:179-182

84. European Medicines Agency Rotarix. Scientific discussion. http://www.ema.europa.eu/docs/ en_GB/document_library/EPAR_-_Scientific Discussion/human/000639/WC500054589.pdf. Accessed: 230 Apr 2013 (11 Sept 2006)

85. Clark HF, Furukawa T, Bell LM et al (1986) Immune response of infants and children to lowpassage bovine rotavirus (strain WC3). Am J Dis Child 140:350-356

86. Heaton PM, Ciarlet M (2007) The pentavalent rotavirus vaccine: discovery to licensure and beyond. Clin Infect Dis 45:1618-1624

87. European Medicines Agency (21 September 2006) Rotateq: Scientific discussion. http:// www.ema.europa.eu/docs/en_GB/document_ library/EPAR_-_Scientific_Discussion/human/000669/WC500054183.pdf. Accessed: 23 Apr 2013
88. Victoria JG, Wang C, Jones MS et al (2010) Viral nucleic acids in live-attenuated vaccines: detection of minority variants and an adventitious virus. J Virol 84:6033-6040

89. European Medicines Agency European Medicines Agency confirms positive benefit-risk balance of Rotarix. Porcine circovirus type 1 in the oral vaccine poses no risk to public health. http://www.ema.europa. eu/ema/index.jsp?curl=pages/news and events/news/2010/03/news_detail_001011. jsp\&mid=WC0b01ac058004d5c1. Accessed: 28 Mar 2012 (22 Jul 2010)

90. European Medicines Agency (23 Sept 2010) European Medicines Agency confirms positive benefit-risk balance of RotaTeq. Very low levels of porcine circovirus type 2 DNA fragments in the oral vaccine pose no risk to public health. http://www.ema.europa. eu/ema/index.jsp?curl=pages/news_and events/news/2010/09/news detail 001121. jsp\&mid=WC0b01ac058004d5c1. Accessed: 28 Mar 2012

91. German Standing Committee on Vaccination (STIKO) Standard Operating Procedure of the German Standing Committee on Vaccinations (STIKO) for the systematic development of vaccination recommendations (Standardvorgehensweise (SOP) der Ständigen Impfkommission (STIKO) für die systematische Entwicklung von Impfempfehlungen. http://rki.de/EN/Content/Prevention/Vaccination/methodology/SOP. pdf. Accessed: 2e Apr 2013 (10 Nov 2011)

92. Guyatt $\mathrm{GH}$, Oxman AD, Kunz R et al (2011) GRADE guidelines: 2 . Framing the question and deciding on important outcomes. J Clin Epidemiol 64:395-400

93. Higgins JP, Thompson SG, Deeks JJ, Altman DG (2003) Measuring inconsistency in meta-analyses. BMJ 327:557-560

94. Balshem $\mathrm{H}$, Helfand $\mathrm{M}$, Schunemann $\mathrm{HJ}$ et al (2011) GRADE guidelines: 3. Rating the quality of evidence. J Clin Epidemiol 64:401-406

95. Ciarlet M, Sani-Grosso R, Yuan G et al (2008) Concomitant use of the oral pentavalent human-bovine reassortant rotavirus vaccine and oral poliovirus vaccine. Pediatr Infect Dis J 27:874-880

96. European Medicines Agency RotaTeq. http:// www.ema.europa.eu/docs/en_GB/document library/EPAR_-_Product_Information/human/000669/WC500054185.pdf. Accessed: 30 Mar 2012 (23 March 2012 (last update))

97. European Medicines Agency Rotarix. http:// www.ema.europa.eu/docs/en_GB/document library/EPAR_-_Product_Information/human/000639/WC500054789.pdf. Accessed: 30 Mar 2012 (20 October 2011 (last update))

98. Clark HF, Borian FE, Bell LM et al (1988) Protective effect of WC3 vaccine against rotavirus diarrhea in infants during a predominantly serotype 1 rotavirus season. J Infect Dis 158:570-587

99. Soares-Weiser $\mathrm{K}$, Maclehose $\mathrm{H}$, Ben-Aharon l et al (2010) Vaccines for preventing rotavirus diarrhoea: vaccines in use. The Cochrane Library 2012, Issue 11. http://www.thecochranelibrary. com

100. Ruiz-Palacios GM, Perez-Schael I, Velazquez FR et al (2006) Safety and efficacy of an attenuated vaccine against severe rotavirus gastroenteritis. N Engl J Med 354:11-22
101. Vesikari T, Matson DO, Dennehy P et al (2006) Safety and efficacy of a pentavalent human-bovine (WC3) reassortant rotavirus vaccine. $\mathrm{N}$ Engl J Med 354:23-33

102. Kawamura N, Tokoeda Y, Oshima M et al (2011) Efficacy, safety and immunogenicity of RIX4414 in Japanese infants during the first two years of life. Vaccine 29:6335-6341

103. Phua KB, Lim FS, Lau YL et al (2009) Safety and efficacy of human rotavirus vaccine during the first 2 years of life in Asian infants: randomised, double-blind, controlled study. Vaccine 27:5936-5941

104. Vesikari T, Karvonen A, Prymula R et al (2007) Efficacy of human rotavirus vaccine against rotavirus gastroenteritis during the first 2 years of life in European infants: randomised, doubleblind controlled study. Lancet 370:1757-1763

105. Block SL, Vesikari T, Goveia MG et al (2007) Efficacy, immunogenicity, and safety of a pentavalent human-bovine (WC3) reassortant rotavirus vaccine at the end of shelf life. Pediatr 119:1118

106. Guyatt $\mathrm{GH}$, Oxman $A D$, Kunz R et al (2011) GRADE guidelines: 7. Rating the quality of evidence-inconsistency. J Clin Epidemiol 64:12941302

107. Linhares AC, Velazquez FR, Perez-Schael I et al (2008) Efficacy and safety of an oral live attenuated human rotavirus vaccine against rotavirus gastroenteritis during the first 2 years of life in Latin American infants: a randomised, doubleblind, placebo-controlled phase III study. Lancet 371:1181-1189

108. Vesikari T, Itzler R, Matson DO et al (2007) Efficacy of a pentavalent rotavirus vaccine in reducing rotavirus-associated health care utilization across three regions (11 countries). J Infect Dis 11(Suppl 2):S29-S35

109. Vesikari T, Karvonen A, Puustinen L et al (2004) Efficacy of RIX4414 live attenuated human rotavirus vaccine in Finnish infants. Pediatr Infect Dis J 23:937-943

110. Boom JA, Tate JE, Sahni LC et al (2010) Sustained protection from pentavalent rotavirus vaccination during the second year of life at a large, urban United States pediatric hospital. Pediatr Infect Dis J 29:1133-1135

111. Castilla J, Beristain $X$, Martinez-Artola V et al (2012) Effectiveness of rotavirus vaccines in preventing cases and hospitalizations due to rotavirus gastroenteritis in Navarre, Spain. Vaccine 30:539-543

112. Cortese MM, LeBlanc J, White KE et al (2011) Leveraging state immunization information systems to measure the effectiveness of rotavirus vaccine. Pediatr 128:1474-1481

113. Desai SN, Esposito DB, Shapiro ED et al (2010) Effectiveness of rotavirus vaccine in preventing hospitalization due to rotavirus gastroenteritis in young children in Connecticut, USA. Vaccine 28:7501-7506

114. Guh AY, Hadler JL (2011) Use of the state immunization information system to assess rotavirus vaccine effectiveness in Connecticut, 20062008. Vaccine 29:6155-6158

115. Martinón-Torres F, Bouzón Alejandro M, Redondo Collazo L et al (2011) Effectiveness of rotavirus vaccination in Spain. Hum Vaccin 7:757-761 
116. Muhsen K, Shulman L, Kasem E et al (2010) Effectiveness of rotavirus vaccines for prevention of rotavirus gastroenteritis-associated hospitalizations in Israel: a case-control study. Hum Vaccin 6:450-454

117. Staat MA, Payne DC, Donauer S et al (2011) Effectiveness of pentavalent rotavirus vaccine against severe disease. Pediatr 128:267-275

118. Field EJ, Vally H, Grimwood K, Lambert SB (2010) Pentavalent rotavirus vaccine and prevention of gastroenteritis hospitalizations in Australia. Pediatr 126:506-512

119. Gagneur A, Nowak E, Lemaitre T et al (2011) Impact of rotavirus vaccination on hospitalizations for rotavirus diarrhea: the IVANHOE study. Vaccine 29:3753-3759

120. Wang FT, Mast TC, Glass RJ et al (2010) Effectiveness of the pentavalent rotavirus vaccine in preventing gastroenteritis in the United States. Pediatr 125:208-213

121. Begue RE, Perrin K (2010) Reduction in gastroenteritis with the use of pentavalent rotavirus vaccine in a primary practice. Pediatr 126:e40 e45

122. Braeckman T, Van Herck K, Raes M et al (2011) Rotavirus vaccines in Belgium: policy and impact. Pediatr Infect Dis J 30:21-24

123. Hanquet $G$, Ducoffre G, Vergison A et al (2011) Impact of rotavirus vaccination on laboratory confirmed cases in Belgium. Vaccine 29:46984703

124. Trimis G, Koutsoumbari I, Kottaridi C et al (2011) Hospital-based surveillance of rotavirus gastroenteritis in the era of limited vaccine uptake through the private sector. Vaccine 29:72927295

125. Paulke-Korinek $M$, Rendi-Wagner $P$, Kundi $M$ et al (2010) Universal mass vaccination against rotavirus gastroenteritis: impact on hospitalization rates in austrian children. Pediatr Infect Dis J 29:319-323

126. Belshaw DA, Muscatello DJ, Ferson MJ, Nurkic A (2009) Rotavirus vaccination one year on. Commun Dis Intell 33:337-340

127. Buttery JP, Lambert SB, Grimwood K et al (2011) Reduction in rotavirus-associated acute gastroenteritis following introduction of rotavirus vaccine into Australia's National Childhood vaccine schedule. Pediatr Infect Dis J 30:25-29

128. Clarke MF, Davidson GP, Gold MS, Marshall HS (2011) Direct and indirect impact on rotavirus positive and all-cause gastroenteritis hospitalisations in South Australian children following the introduction of rotavirus vaccination. Vaccine 29:4663-4667

129. Lambert $S B$, Faux $C E$, Hall L et al (2009) Early evidence for direct and indirect effects of the infant rotavirus vaccine program in Queensland. Med J Aust 191:157-160

130. Macartney KK, Porwal M, Dalton D et al (2011) Decline in rotavirus hospitalisations following introduction of Australia's national rotavirus immunisation programme. J Paediatr Child Health 47:266-270

131. Anderson EJ, Rupp A, Shulman ST et al (2011) Impact of rotavirus vaccination on hospital-acquired rotavirus gastroenteritis in children. $\mathrm{Pe}$ diatr 127:264-270

132. Centers for Disease C, Prevention (2008) Delayed onset and diminished magnitude of rotavirus activity-United States, November 2007May 2008. MMWR Morb Mortal Wkly Rep 57:697-700
133. Chang HG, Smith PF, Tserenpuntsag B et al (2010) Reduction in hospitalizations for diarrhea and rotavirus infections in New York state following introduction of rotavirus vaccine. Vaccine 28:754-758

134. Clark HF, Lawley D, Mallette LA et al (2009) Decline in cases of rotavirus gastroenteritis presenting to The Children's Hospital of Philadelphia after introduction of a pentavalent rotavirus vaccine. Clin Vaccine Immunol 16:382-386

135. Payne DC, Staat MA, Edwards KM et al (2011) Direct and indirect effects of rotavirus vaccination upon childhood hospitalizations in 3 US Counties, 2006-2009. Clin Infect Dis 53:245-253

136. Tate JE, Mutuc JD, Panozzo CA et al (2011) Sustained decline in rotavirus detections in the United States following the introduction of rotavirus vaccine in 2006. Pediatr Infect Dis J 30:30-34

137. Yen C, Tate JE, Wenk JD et al (2011) Diarrhea-associated hospitalizations among US Children over 2 rotavirus seasons after vaccine introduction. Pediatr 127:9-15

138. Quintanar-Solares M, Yen C, Richardson V et al (2011) Impact of rotavirus vaccination on diarrhea-related hospitalizations among children $<5$ years of age in Mexico. Pediatr Infect Dis J 30:11-15

139. Richardson V, Hernandez-Pichardo J, QuintanarSolares M et al (2010) Effect of rotavirus vaccination on death from childhood diarrhea in Mexico. N Engl J Med 362:299-305

140. Richardson V, Parashar U, Patel M (2011) Childhood diarrhea deaths after rotavirus vaccination in Mexico. N Engl J Med 365:772-773

141. Cortes J, Esposito D, Cortese M et al (2010) Uptake and impact of rotavirus vaccines in US Children. Int J Infect Dis 14:175-176

142. Dudareva-Vizule $S$, Koch J, An der Heiden $M$ et al (2012) Impact of rotavirus vaccination in regions with low and moderate vaccine uptake in Germany. Hum Vaccin Immunother 8(10):14071415

143. Adlhoch C, Hoehne M, Littmann M et al (2012) Rotavirus vaccine effectiveness and case-control study on risk factors for breakthrough-infections in Germany. Pediatr Infect Dis J 32:e82e89

144. Farrington CP (1993) Estimation of vaccine effectiveness using the screening method. Int J Epidemiol 22:742-746

145. Bines JE, Ivanoff B, Justice F, Mulholland K (2004) Clinical case definition for the diagnosis of acute intussusception. J Pediatr Gastroenterol Nutr 39:511-518

146. Centers for Disease C, Prevention (1999) Intussusception among recipients of rotavirus vaccine-United States, 1998-1999. MMWR Morb Mortal Wkly Rep 48:577-581

147. Kramarz P, France EK, Destefano F et al (2001) Population-based study of rotavirus vaccination and intussusception. Pediatr Infect Dis J 20:410-416

148. Weiß S, Streng A, Kries RV et al (2011) Inzidenz der Invagination bei Säuglingen in Deutschland. Eine Schätzung anhand der Capture-RecaptureMethode. Klin Padiatr 223:419-423

149. Belongia $\mathrm{E}$, Izurieta $\mathrm{H}$, Braun $\mathrm{MM}$ et al (2007) Postmarketing monitoring of intussusception after RotaTeq ${ }^{\mathrm{TM}}$ vaccination-United States, February 1, 2006-February 15, 2007. MMWR Morb Mortal Wkly Rep 56:218-222
150. Belongia EA, Irving SA, Shui IM et al (2010) Realtime surveillance to assess risk of intussusception and other adverse events after pentavalent bovine-derived rotavirus vaccine. Pediatr Infect Dis J 29:1-5

151. Haber P, Patel M, Izurieta HS et al (2008) Postlicensure monitoring of intussusception after RotaTeq vaccination in the United States, February 1, 2006, to September 25, 2007. Pediatr 121:1206-1212

152. Loughlin J, Mast C, Doherty M et al (2012) Post marketing evaluation of the short-term safety of the pentavalent rotavirus vaccine. Pediatr Infect Dis J 31:292-296

153. Shui IM, Baggs J, Patel M et al (2012) Risk of intussusception following administration of a pentavalent rotavirus vaccine in US infants. JAMA 307:598-604

154. Buttery JP, Danchin MH, Lee KJ et al (2011) Intussusception following rotavirus vaccine administration: post-marketing surveillance in the National Immunization Program in Australia. Vaccine 29:3061-3066

155. Carlin JLK (2011) Rotavirus vaccination and risk of intussusception. Australian Government; Department of Health and Ageing; Therapeutic Goods Administration. http://www.tga.gov.au/ safety/alerts-medicine-rotavirus-110225.htm. Accessed: 23 Apr 2013

156. Patel MM, López-Collada VR, Bulhões MM et al (2011) Intussusception risk and health benefits of rotavirus vaccination in Mexico and Brazil. N Engl J Med 364:2283-2292

157. WHO (2007) Rotavirus vaccines. WHO position paper. Wkly Epidemiol Rec 82:285-296

158. Oberle D, Weisser K, Keller-Stanislawski B (2010) Aktuelle Erkenntnisse zum Risiko für Invagination und Kawasaki-Syndrom nach Rotavirusimpfung. Arzneimittel im Blick 8-13

159. Rowley AH, Shulman ST (2010) Pathogenesis and management of Kawasaki disease. Expert Rev Anti Infect Ther 8:197-203

160. Yanagawa $\mathrm{H}$, Nakamura $Y$, Yashiro M et al (2006) Incidence of Kawasaki disease in Japan: the nationwide surveys of 1999-2002. Pediatr Int 48:356-361

161. Baig A, Abuhammour W (2008) Kawasaki disease. Pediatr Infect Dis J 3:5-12

162. Hua W, Izurieta HS, Slade B et al (2009) Kawasaki disease after vaccination: reports to the vaccine adverse event reporting system 19902007. Pediatr Infect Dis J 28:943-947

163. Pollard AJ, Finn A (eds) (2006) Hot topics in infection and immunity in children III. In: Advances in Experimental Medicine and Biology. Springer Verlag, Heidelberg, Vol 582

164. Seyberth HW, Ludwig WD, Gundert-Remy U et al (2010) Kawasaki Syndrom nach RotaTeq ${ }^{\mathbb{B}}$ Impfung: Bereits Verdachtsfalle melden Kawasaki syndrome following RotaTeq ${ }^{\circledR}$ vaccination: suspected cases also to be reported. Monatsschrift Kinderheilkund 158:1252

165. Oberle D, Ponisch C, Weier K et al (2010) Schutzimpfung gegen Rotavirusgastroenteritis: Assoziation mit dem Kawasaki-Syndrom? Vaccination against gastroenteritis caused by rotavirus: association with Kawasaki disease? Monatsschrift Kinderheilkund 158:1253-1260

166. Newman RD, Grupp-Phelan J, Shay DK, Davis RL (1999) Perinatal risk factors for infant hospitalization with viral gastroenteritis. Pediatr 103:E3 
167. Goveia MGM, Rodriguez ZMM, Dallas MJP et al (2007) Safety and efficacy of the pentavalent human-bovine (WC3) reassortant rotavirus vaccine in healthy premature infants. Pediatr Infect Dis J 26:1099-1104

168. Omenaca F, Sarlangue J, Szenborn L et al (2012) Safety, reactogenicity and immunogenicity of the human rotavirus vaccine in preterm European Infants: a randomized phase Illb study. Pediatr Infect Dis J 31:487-493

169. Velazquez FR, Matson DO, Calva JJ et al (1996) Rotavirus infections in infants as protection against subsequent infections. $N$ Engl J Med 335:1022-1028

170. Bakare N, Menschik D, Tiernan R et al (2010) Severe combined immunodeficiency (SCID) and rotavirus vaccination: reports to the Vaccine Adverse Events Reporting System (VAERS). Vaccine 28:6609-6612

171. Centers for Disease C, Prevention (2010) Addition of severe combined immunodeficiency as a contraindication for administration of rotavirus vaccine. MMWR Morb Mortal Wkly Rep 59:687688

172. Committee on Infectious Diseases (2009) Prevention of Rotavirus Disease: updated guidelines for use of rotavirus vaccine. Pediatr 123:1412-1420

173. Anderson EJ (2008) Rotavirus vaccines: viral shedding and risk of transmission. Lancet Infect Dis 8:642-649

174. Briggs A, Sculpher M (1998) An introduction to Markov modelling for economic evaluation. PharmacoEconomics 13:397-409

175. Clark HF, Bernstein DI, Dennehy PH et al (2004) Safety, efficacy, and immunogenicity of a live, quadrivalent human-bovine reassortant rotavirus vaccine in healthy infants. J Pediatr 144:184-190

176. Clark HF, Burke CJ, Volkin DB et al (2003) Safety, immunogenicity and efficacy in healthy infants of $\mathrm{G} 1$ and $\mathrm{G} 2$ human reassortant rotavirus vaccine in a new stabilizer/buffer liquid formulation. Pediatr Infect Dis J 22:914-920

177. Vesikari T, Itzler R, Karvonen A et al (2009) RotaTeq ${ }^{\mathrm{TM}}$, a pentavalent rotavirus vaccine: efficacy and safety among infants in Europe. Vaccine 28:345-351

178. Vesikari T, Karvonen A (2004) Efficacy of RIX4414 live attenuated human rotavirus vaccine in Finnish infants. Pediatr Infect Dis J 23:937-943

179. Vesikari T, Karvonen A (2004) Safety and immunogenicity of RIX4414 live attenuated human rotavirus vaccine in adults, toddlers and previously uninfected infants. Vaccine 22:2836-2842

180. Dennehy PH, De Vos B, Brady RC et al (2005) Comparative evaluation of safety and immunogenicity of two dosages of an oral live attenuated human rotavirus vaccine. Pediatr Infect Dis J 24:481-488

181. Ciarlet M, He S, Lai S et al (2009) Concomitant use of the 3-dose oral pentavalent rotavirus vaccine with a 3-dose primary vaccination course of a diphtheria-tetanus-acellular pertussis-hepatitis B-inactivated polio-haemophilus influenzae type $b$ vaccine: immunogenicity and reactogenicity. Pediatr Infect Dis J 28:177-181

182. Martin A, Cottrell S, Standaert B (2008) Estimating utility scores in young children with acute rotavirus gastroenteritis in the UK. J Med Econ 11:471-484
183. Goossens LM, Standaert B, Hartwig $N$ et al (2008) The cost-utility of rotavirus vaccination with Rotarix (RIX4414) in the Netherlands. Vaccine 26:1118-1127

184. Patel MM, Haber P, Baggs J et al (2009) Intussusception and rotavirus vaccination: a review of the available evidence. Expert Rev Vaccines 8:1555-1564

185. Diez-Domingo J, Surinach NL, Alcalde NM et al (2010) Burden of paediatric rotavirus gastroenteritis (RVGE) and potential benefits of a universal rotavirus vaccination programme with a pentavalent vaccine in Spain. BMC Public Health 10:469

186. Poggensee $G$, Benzler J, Eckmanns T, Krause $\mathrm{G}$ (2006) On the 2007 edition of case definitions for the surveillance of notifiable infectious diseases in Germany. Bundesgesundheitsblatt Gesundheitsforschung Gesundheitsschutz 49:1189-1194

187. Weisser K, Meyer C, Petzold D et al (2007) Adverse drug reactions following immunization in Germany pursuant to the German Infection Protection Act and the German Medicinal Products Act from January 1, 2004 to December 31, 2005. Bundesgesundheitsblatt Gesundheitsforschung Gesundheitsschutz 50:1404-1417

188. Keller-Stanislawski B, Heuss N, Meyer C (2004) Adverse events following immunisation in Germany from 01.01.2001 to 31.12.2003. Bundesgesundheitsblatt Gesundheitsforschung Gesundheitsschutz 47:1151-1164

189. Evans SJ, Waller PC, Davis S (2001) Use of proportional reporting ratios (PRRs) for signal generation from spontaneous adverse drug reaction reports. Pharmacoepidemiol Drug Saf 10:483-486

190. Reiter S, Poethko-Muller C (2009) Current vaccination coverage and immunization gaps of children and adolescents in Germany. Bundesgesundheitsblatt Gesundheitsforschung Gesundheitsschutz 52:1037-1044 